\title{
Siglec-G represses DAMP-mediated effects on T cells
}

\author{
Tomomi Toubai, ${ }^{1}$ Corinne Rossi, ${ }^{1}$ Katherine Oravecz-Wilson, ${ }^{1}$ Cynthia Zajac, ${ }^{1}$ Chen Liu, ${ }^{2}$ \\ Thomas Braun, ${ }^{3}$ Hideaki Fujiwara, ${ }^{1}$ Julia Wu, ${ }^{1}$ Yaping Sun, ${ }^{1}$ Stuart Brabbs, ${ }^{1}$ Hiroya Tamaki, ${ }^{4}$ \\ John Magenau, ${ }^{1}$ Pang Zheng, ${ }^{5}$ Yang Liu, ${ }^{5}$ and Pavan Reddy ${ }^{1}$ \\ 'Department of Internal Medicine, University of Michigan Comprehensive Cancer Center, Ann Arbor, Michigan, USA. \\ 2Department of Pathology and Laboratory Medicine, Rutgers-Robert Wood Johnson Medical School, New Brunswick, \\ New Jersey, USA. ${ }^{3}$ Department of Biostatistics, School of Public Health, University of Michigan, Ann Arbor, USA. \\ ${ }^{4}$ Division of Hematology, Department of Internal Medicine, Hyogo College of Medicine, Hyogo, Japan. ${ }^{5}$ Center for Cancer \\ and Immunology Research, Children's National Medical Center, Washington DC, USA.
}

The role of negative regulators or suppressors of the damage-associated molecular patternmediated (DAMP-mediated) stimulation of innate immune responses is being increasingly appreciated. However, the presence and function of suppressors of DAMP-mediated effects on T cells, and whether they can be targeted to mitigate $\mathrm{T}$ cell-dependent immunopathology remain unknown. Sialic acid-binding immunoglobulin-like lectin $G$ (Siglec-G) is a negative regulator of DAMP-mediated responses in innate immune cells, but its T cell-autonomous role is unknown. Utilizing loss-of-function-based (genetic knockout) and gain-of-function-based (agonist) approaches, we demonstrate that in the presence of certain DAMPs, Siglec- $G$ suppressed in vitro and in vivo $\mathrm{T}$ cell responses. We also demonstrate that its $\mathrm{T}$ cell-autonomous role is critical for modulating the severity of the T cell-mediated immunopathology, graft-versus-host disease (GVHD). Enhancing the Siglec-G signaling in donor T cells with its agonist, a CD24Fc fusion protein, ameliorated GVHD while preserving sufficient graft-versus-tumor (CVT) effects in vivo. Collectively, these data demonstrate that Siglec- $\mathrm{C}$ is a potentially novel negative regulator of $\mathrm{T}$ cell responses, which can be targeted to mitigate GVHD.

Authorship note: T. Toubai and C. Rossi have contributed equally to this project.

Conflict of interest: The authors have declared that no conflict of interest exists.

Submitted: December 14, 2016 Accepted: June 8, 2017 Published: July 20, 2017

\section{Reference information:} JCI Insight. 2017;2(14):e92293. https://doi.org/10.1172/jci. insight.92293.

\section{Introduction}

Innate immune receptors such as Toll-like receptors (TLRs) on immune cells play critical roles in initiating inflammatory responses to damage- and pathogen-associated molecular patterns (DAMPs and PAMPs, respectively) (1). It is well understood that TLR signaling in antigen-presenting cells (APCs) enhances $\mathrm{T}$ cell responses. In addition, TLR stimulation with PAMPs has been reported to enhance $\mathrm{T}$ cell functions in a cell-autonomous manner (2). However, direct effects on $\mathrm{T}$ cell responses, either positive or negative, by DAMPs have not been demonstrated.

Sialic acid-binding immunoglobulin-like lectins (Siglecs) have immunoreceptor tyrosine-based inhibitory motifs (ITIMs) or ITIM-like regions in their intracellular domains and negatively regulate, i.e., suppress, innate or B cell immune responses (3-6). They play a pivotal role in suppressing DAMP-mediated innate inflammatory responses (7-9) and in inducing B cell tolerance $(6,10)$. However, whether Siglecs, specifically, Siglec-G, are expressed by $\mathrm{T}$ cells and if so, whether they have $\mathrm{T}$ cell-autonomous functions, and furthermore whether such a function can be targeted to mitigate in vivo pathological processes, remain unknown.

In allogeneic hematopoietic stem cell transplantation (all-HCT), host tissue injuries caused by underlying disease and conditioning regimens lead to the release of proinflammatory cytokines (11), DAMPs $(12,13)$, and PAMPs (14). Both DAMP- and PAMP-mediated activation of APCs $(12,13,15)$ has been shown to aggravate acute GVHD $(16,17)$. Suppression of DAMP-mediated effects on APCs by Siglecs on hematopoietically derived APCs is crucial for controlling GVHD (18). However, whether suppression of DAMP effects specifically and directly only on T cells can also affect GVHD is not known. 


\section{Results}

$T$ cells express Siglec-G and it represses their responses in the presence of DAMPs. It remains unknown whether $\mathrm{T}$ cells respond to DAMPs. We made the potentially novel observation that naive T cells from B6 WT animals expressed the negative regulator of DAMP responses, Siglec-G mRNA (Figure 1A). We next examined whether naive $\mathrm{T}$ cells express Siglec-G protein by FACS using a monoclonal antibody against Siglec-G (clone SH2.1). To this end, we used Siglec-G-deficient (Siglec-G ${ }^{-/-}$) T cells as negative controls, B cells as positive controls, and antibody titrations from 100- to 1,000-fold dilution and found that in contrast to some previous reports $(19,20)$, but consistent with another report $(5)$, that about $16 \% \pm 2.6 \%$ of naive $\mathrm{T}$ cells expressed Siglec-G protein (Figure 1B and Supplemental Figure 1, A-G; supplemental material available online with this article; https://doi.org/10.1172/jci.insight.92293DS1).

We next analyzed the Siglec-G-deficient B6 animals to determine whether Siglec-G is essential for T cell development or differentiation at homeostasis. Absence of Siglec-G did not affect the numbers or distribution of naive, central memory, effector memory, and Treg cells (Supplemental Figure 2, A-H). We then examined whether Siglec-G had any functional effect on naive T cells. Siglec- $\mathrm{G}^{-/-}$naive $\mathrm{T}$ cells showed proliferation similar to that of WT T cells in vitro following stimulation with anti-CD3/CD28 antibodies or allogeneic BALB/c-derived bone marrow-derived DCs (BMDCs) (Figure 1, C and D). Because Siglec-G is an important negative regulator of stimulation by DAMPs $(3,4)$, we next determined whether the absence of Siglec-G on naive T cells affected their proliferative responses in the presence of DAMPs. To determine this, and to rule out indirect effects of DAMPs in APCs, we added high mobility group box 1 protein (HMGB-1), a well-characterized DAMP, to anti-CD3/CD28 antibody-mediated stimulation of $\mathrm{T}$ cells. Siglec- $\mathrm{G}^{-/} \mathrm{T}$ cells exhibited significantly greater proliferation in the presence of HMBG-1 when compared with Siglec- $\mathrm{G}^{-1} \mathrm{~T}$ cells without DAMPs or the WT T cells regardless of the presence of DAMPs (Figure $1 \mathrm{E}$ and Supplemental Figure 3A). The WT T cells exhibited greater expression of Siglec-G when treated with the DAMP HMBG-1 (Figure 1F). These data collectively suggest that DAMP stimulation enhances the expression of its negative regulator Siglec-G, in the absence of which they show more enhanced $\mathrm{T}$ cell expansion. The negative signaling by the Siglec-G ITIM is mediated by its phosphorylation through recruitment of SHP-1 and SHP-2. Therefore, we next examined whether T cells, when stimulated in the presence of the DAMP HMBG-1, changed the ratios of SHP-1 and SHP-2 to phosphorylated SHP-1 (p-SHP-1) and p-SHP-2. When compared with WT T cells, upon stimulation the expression of p-SHP-1 and p-SHP-2 was reduced in the Siglec- $\mathrm{G}^{-/-} \mathrm{T}$ cells (Figure 1, Supplemental Figure 3D, and Supplemental Figure 4, A-C). By contrast, p-signal transducer and activator of transcription 3 (STAT3) was increased in both WT and Siglec- $\mathrm{G}^{-1-} \mathrm{T}$ cells, albeit to a greater extent in the KO than WT cells, but no such increase was observed in the activating signaling pathways such as in expression of lymphocyte-specific protein tyrosine kinase (LCK) in the presence of HMBG-1 (Supplemental Figure 3, B and C). Furthermore, in the presence of the DAMP HMBG-1, Siglec-G ${ }^{-/-}$T cells showed higher activation, but showed similar expression of exhaustion markers such as programmed cell death protein 1 (PD-1) (Figure 1H), T cell immunoreceptor with Ig and ITIM domains (TIGIT), or lymphocyte-activation gene 3 (Lag3) (Supplemental Figure 3, E and F) when compared with WT T cells. These data suggest that in the presence of DAMPs, Siglec-G/ITIM signaling was increased without an increase in activation signaling or the exhaustion markers.

Siglec-G regulates in vivo $T$ cell responses in a cell-autonomous manner. We next determined whether deficiency of Siglec-G on T cells altered their responses in vivo, in the presence of DAMPs and lymphopenia both with and without non-self antigen-driven TCR stimulation. Because host tissue injuries caused by the conditioning regimen lead to the release of DAMPs $(12,13,18)$, we used lethally irradiated hosts to generate DAMPs from radiation-induced damage. The congenic B6 WT hosts were lethally irradiated and transplanted with naive T cells from syngeneic B6 WT or Siglec- $\mathrm{G}^{-/-}$donors to determine whether absence of Siglec-G would alter $\mathrm{T}$ cell responses in vivo in the presence of DAMPs and lymphopenia, but in the absence of non-self antigen-driven TCR stimulation. Donor T cell expansion and activation $\left(\mathrm{CD}^{2} 9^{+}\right)$in the spleen and intestinal epithelial cells (IELs) was similar in both the recipients of WT and Siglec-G-deficient syngeneic animals (Supplemental Figure 5, A-C). These data suggested that in the absence of antigen-driven TCR stimulation, deficiency of Siglec-G did not lead to alteration of in vivo T cell responses when compared with WT T cells. We next determined whether Siglec-G regulates in vivo $\mathrm{T}$ cell responses following antigen-driven $\mathrm{T}$ cell stimulation (allostimulation) in the presence of DAMPs. We utilized, once again, lethal irradiation as conditioning regimen to release DAMPs $(12,13,18)$ and we tested the hypothesis that Siglec- $\mathrm{G}^{-/-}$donor T cells will show enhanced proliferation in the context of release of DAMPs and allostimulation. We utilized the 
A

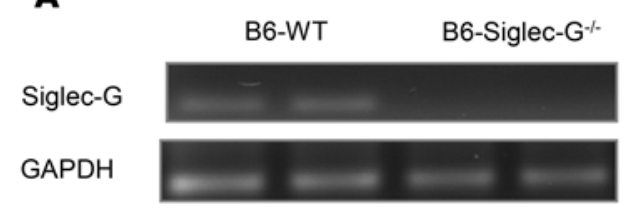

E

$\mathrm{CD} 3 / \mathrm{CD} 28(24 \mathrm{hr})$
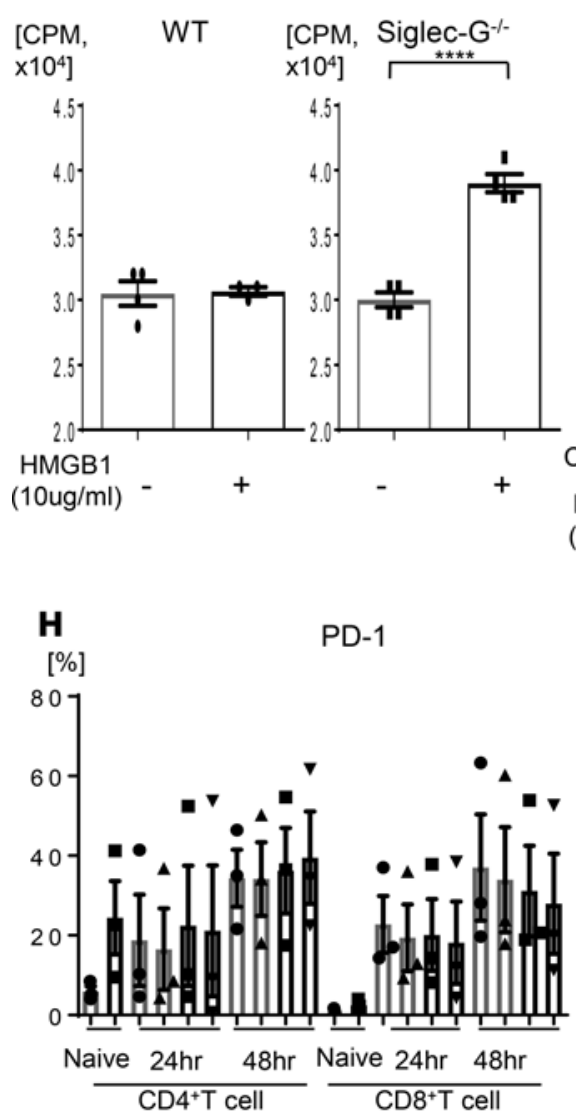

B

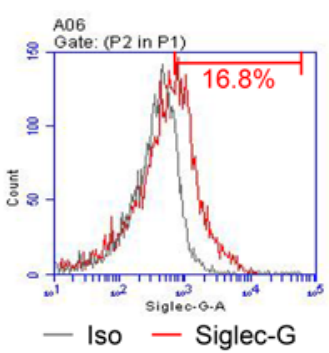

C

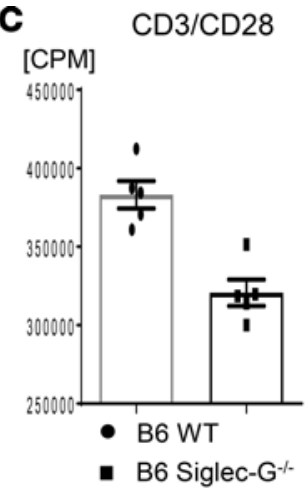

MLR

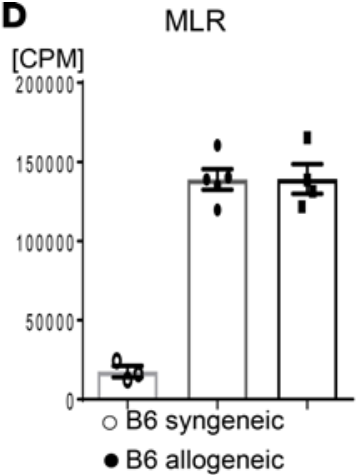

- B6 Siglec- ${ }^{\star}$ allogeneic
F Siglec-G expression

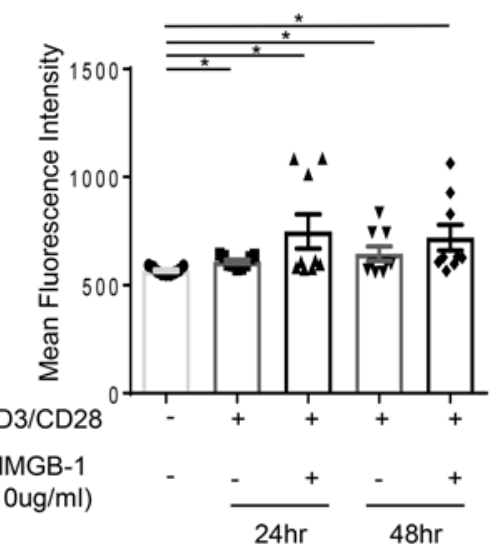

G

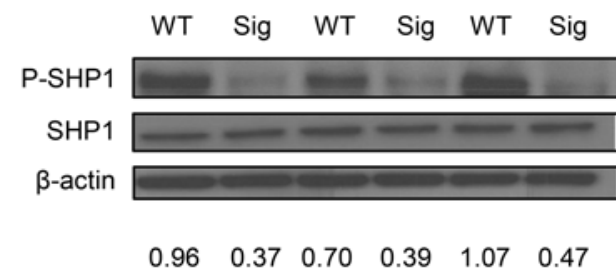

$\mathrm{CD} 3 / \mathrm{CD} 28$

HMGB-1

(10ug/ml)

\section{- B6WT $\|$ B6Siglec-G ${ }^{-1} \quad \Delta$ B6WT+HMGB-1 v B6Siglec-G $-/+$ HMGB-1}

Figure 1. $T$ cells express Siglec- $G$ and it represses their responses in the presence of DAMPs. (A) Naive CD90.2 $2^{+}$cells were isolated from B6 WT spleen with MACS and expression of Siglec- $G$ was evaluated with RT-PCR for Siglec- $G$ mRNA. CAPDH was used as control for RNA loading. Representative data are from 1 of 3 independent experiments. (B) Siglec- $C$ expression of $\mathrm{CD}^{+} \mathrm{T}$ cells in spleen by FACS. Representative data from 3 independent experiments are shown. (C) Isolated splenic CD90.2 $\mathrm{T}$ cells from either B6 WT or Siglec- $\mathrm{C}^{-1-}$ animals were incubated with anti-CD3 $(2 \mu \mathrm{g} / \mathrm{ml})$ and anti-CD28 $(1 \mu \mathrm{g} / \mathrm{ml})$ antibodies for 48 hours and analyzed for proliferation following ${ }^{3} \mathrm{H}$-thymidine incorporation during the last 6 hours of incubation. (D) In vitro mixed lymphocyte reaction (MLR). Isolated splenic CD90.2+ T cells from either B6 WT or Siglec $-\mathrm{G}^{-1-}$ animals were cultured with bone marrow-derived DCs derived from syngeneic B6 or allogeneic $\mathrm{BALB} / \mathrm{c}$ animals for 96 hours and analyzed for proliferation following ${ }^{3} \mathrm{H}$-thymidine incorporation during the last 16 hours of incubation $(P=$ not significant [NS] between groups). (E-I) Isolated splenic CD90.2+ T cells from either B6 WT or Siglec- $\mathrm{C}^{-1-}$ animals were incubated with anti-CD3 (2 $\left.\mu \mathrm{g} / \mathrm{ml}\right)$ and anti-CD28 (1 $\mu \mathrm{g} / \mathrm{ml})$ antibodies in the presence or absence of HMBG-1 $(10 \mu \mathrm{g} / \mathrm{ml})$ for 24 hours and analyzed for proliferation following ${ }^{3} \mathrm{H}$-thymidine incorporation during the last 6 hours of incubation. Representative data from 3 independent experiments are shown. ${ }^{* * *} P<0.001$. (F) Siglec- $G$ expression on T cells was analyzed by FACS at 24 and 48 hours after stimulation. Combined data from 3 independent experiments are shown. ${ }^{*} P<0.0125$, adjusted with Bonferroni correction. (C) Protein expression of phosphorylated $(p)$ and total SHP-1 at 48 hours was evaluated by Western blot. Representative data from 1 of 2 independent experiments are shown. (H) PD-1 expression on $\mathrm{CD}^{+}{ }^{+}$or $\mathrm{CD} 8^{+} T$ cells at 24 and 48 hours after stimulation was analyzed by FACS $(P=\mathrm{NS}$ between groups). Pooled data from 3 independent experiments are shown. Unpaired $t$ test, $P$ value adjusted with Bonferroni correction. Data are shown as the mean \pm SEM. 


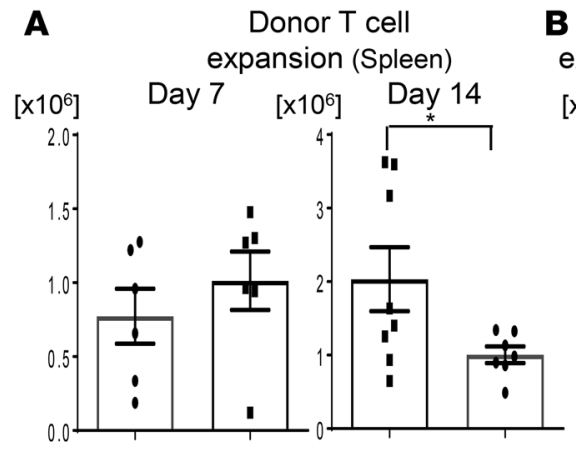

B Donor T cell C
expansion (IEL, Day14)
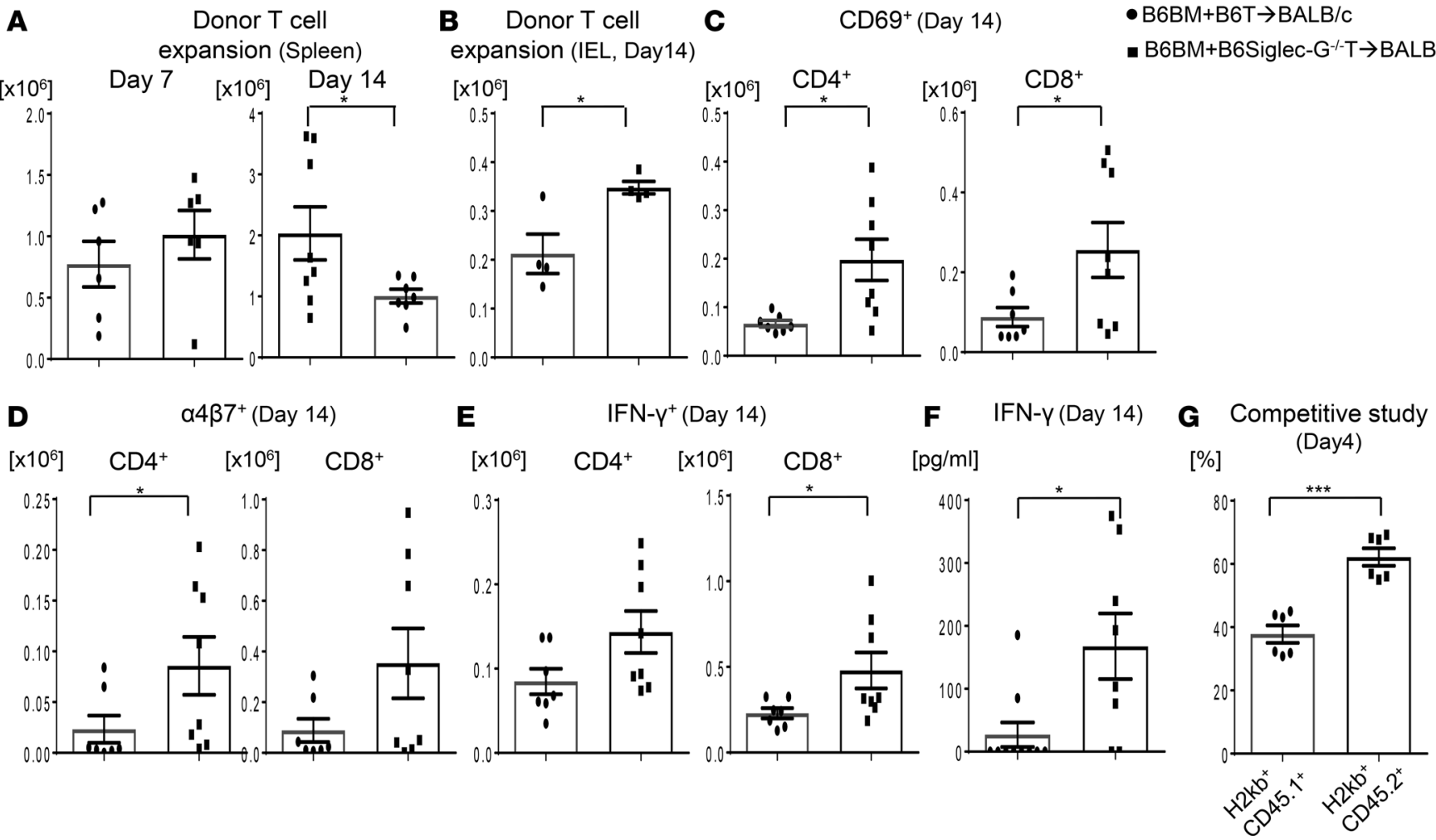

Figure 2. Siglec-G regulates in vivo T cell responses in a cell-autonomous manner. (A-F) BALB/C animals received 8.5 Gy on day -1 and were transplanted with $0.75 \times 10^{6} \mathrm{CD} 90.2^{+}$splenic T cells from either syngeneic BALB/c or allogeneic MHC-mismatched B6 WT or B6 Siglec- $\mathrm{C}^{-1-}$ animals along with $5 \times 10^{6}$ T cell-depleted bone marrow (TCD-BM) cells from either BALB/c or B6 donors. (A and B) Donor T cell $\left(\mathrm{H}-2 \mathrm{~K}^{\mathrm{b}+} \mathrm{CD} 4^{+} \mathrm{CD} 8^{+}\right)$expansion in the spleen $(\mathbf{A})$ and intraepithelial lymphocytes (IELs, B) at days 7 and/or 14 after allogeneic bone marrow transplantation (allo-BMT) ( $n=6-8$ per group, pooled from 2 experiments). (C-E) $\mathrm{CD}^{+} 9^{+}$(C) and $\alpha 4 \beta 7^{+}$(D) expression of donor T cells in the spleen at day 14 after allo-BMT ( $n=7-8$ per group, pooled from 2 experiments). ${ }^{*} P<0.05$. (E) Donor IFN- $\gamma$-producing T cells in the spleen at day 14 after allo-BMT $\left(n=7-8\right.$ per group, pooled from 2 experiments). ${ }^{*} P<0.05$. (F) Serum IFN- $\gamma$ levels at day 14 after allo-BMT ( $n=8-10$ per group, pooled from 3 experiments). ${ }^{*} P<0.05$. (C) T cell competition assay. BALB/c animals were lethally

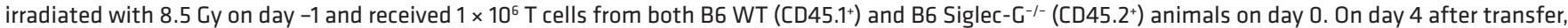
spleens from BALB/C animals were isolated and analyzed. The percentages of $C D 45.1^{+}$and $C D 45.2^{+} T$ cells in the spleen of BALB/c animals are shown. Combined data from 3 individual experiments are shown. Unpaired $t$ test $(\mathbf{A}-\mathbf{G}) .{ }^{*} P<0.05,{ }^{* *} P<0.001$.

well-characterized, irradiated MHC-mismatched $\mathrm{B} 6 \rightarrow \mathrm{BALB} / \mathrm{c}$ model of allogeneic bone marrow transplantation (allo-BMT). BALB/c animals were lethally irradiated and transplanted with WT T cell-depleted bone marrow (TCD-BM) from either syngeneic BALB/c or allogeneic B6 WT animals along with naive allogeneic splenic T cells from either B6 WT or B6-Siglec- $\mathrm{G}^{-/-}$donors. B6 Siglec- $\mathrm{G}^{-/-}$donor T cells that were harvested from allogeneic recipients demonstrated significantly greater expansion in spleen and GVHD target organs gastrointestinal (GI) tract and liver on day +14 after BMT (Figure 2, A and B, and Supplemental Figure 5A), activation $\left(\mathrm{CD} 69^{+}, \alpha 4 \beta 7^{+}\right.$, and CXCR3 $3^{+}$), and secretion of IFN- $\gamma$ when compared with B6 WT T cells after allo-BMT (Figure 2, C-F, Supplemental Figure 5, B and C, and Supplemental Figure 6, A and B). To confirm that the increased expansion of allogeneic B6 Siglec- $\mathrm{G}^{-/-} \mathrm{T}$ cells in the context of DAMP-induced inflammation is a cell-autonomous effect, we next mixed B6 WT $\left(\mathrm{CD} 45.1^{+}\right)$and B6 Siglec- $\mathrm{G}^{-/-}\left(\mathrm{CD} 45.2^{+}\right) \mathrm{T}$ cells in a 1:1 ratio and transferred them into allogeneic BALB/c animals following lethal irradiation. The donor $\mathrm{T}$ cells were harvested on day 4 after transfer. The $\mathrm{CD} 45.2^{+} \mathrm{B} 6$ Siglec- $\mathrm{G}^{-/} \mathrm{T}$ cell demonstrated greater expansion than $\mathrm{CD} 45.1^{+} \mathrm{B} 6 \mathrm{WT}$ T cells (Figure 2G), demonstrating that the increased recovery was because of a cellautonomous effect of the absence of Siglec-G on T cells.

Absence of Siglec-G on donor $T$ cells exacerbates GVHD. We next determined whether the increased expansion of alloreactive Siglec- $\mathrm{G}^{+} \mathrm{T}$ cells in the irradiated host was sufficient to alter $\mathrm{T}$ cell-dependent clinical outcome after allo-BMT, namely GVHD. We utilized the similarly conditioned and MHC-disparate $\mathrm{B} 6 \rightarrow \mathrm{BALB} / \mathrm{c}$ model as above with $0.75 \times 10^{6}$ donor $\mathrm{T}$ cells from the WT or KO donors. The greater response of Siglec- $\mathrm{G}^{+} \mathrm{T}$ cells in the recipient animals was associated with exacerbated GVHD clinical severity and mortality (Figure 3A) when compared with the allorecipients that received WT T cells. To 
A

$B 6 \rightarrow B A L B / c\left(T\right.$ cell $\left.0.75 \times 10^{6}\right)$

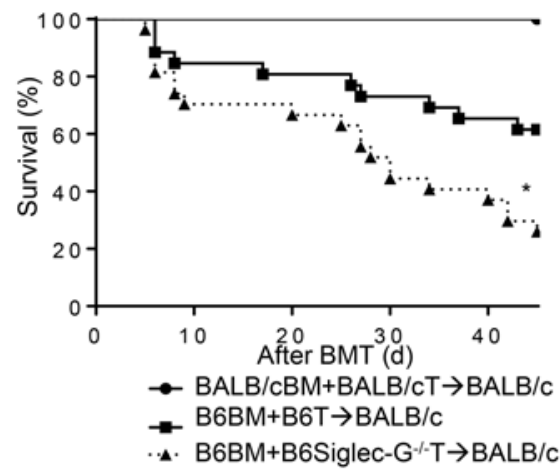

B $\quad B 6 \rightarrow B A L B / c\left(T\right.$ cell $\left.2 \times 10^{6}\right)$

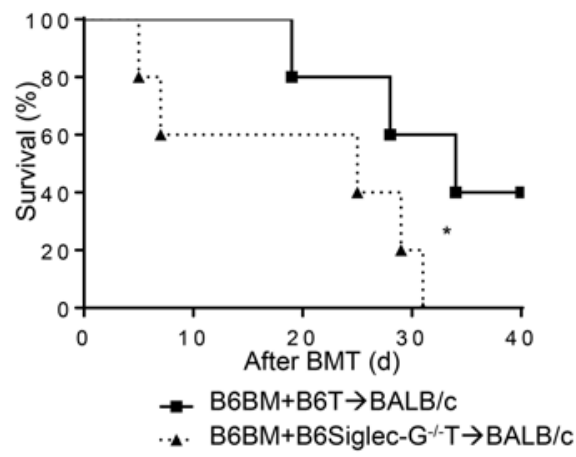

C $B A L B / C B M+B A L B / c T \quad B 6 B M+B 6 T$ $\rightarrow \mathrm{BALB} / \mathrm{c}$ $\rightarrow \mathrm{BALB} / \mathrm{c}$

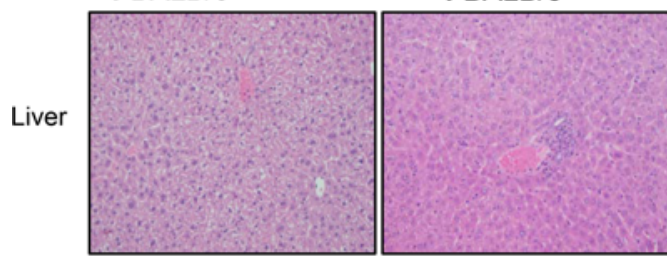

D
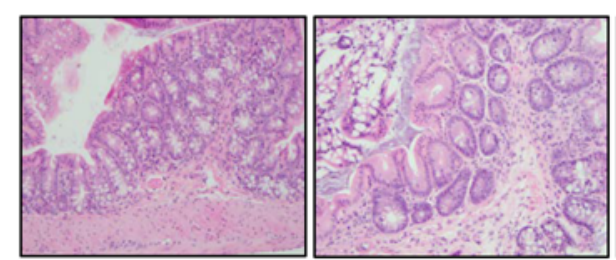

$\mathrm{B} 6 \mathrm{BM}+\mathrm{B} 6$ Siglec- $-\mathrm{G}^{-/} \mathrm{T}$ $\rightarrow \mathrm{BALB} / \mathrm{C}$
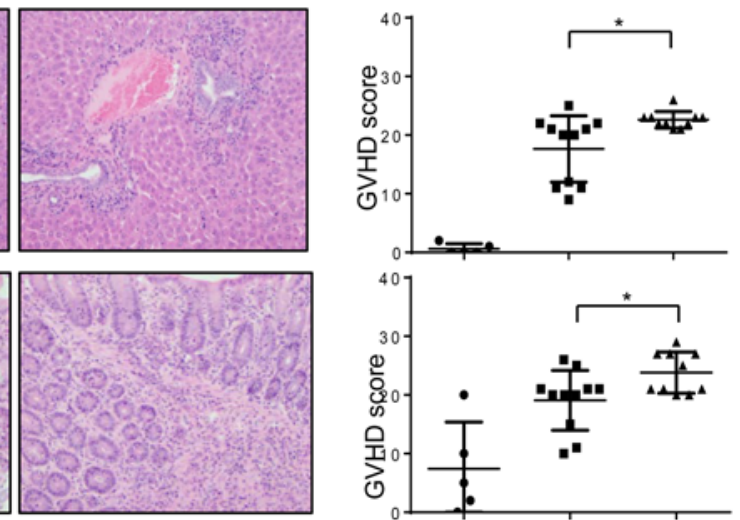

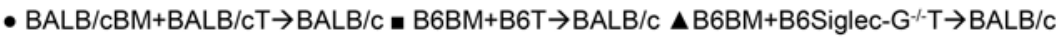

E

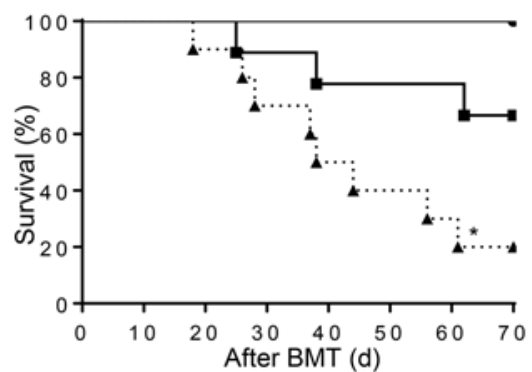

$\rightarrow$ BALB/bBM+BALB/bT $\rightarrow B A L B / b$

$\rightarrow \mathrm{B} 6 \mathrm{BM}+\mathrm{B} 6 \mathrm{~T} \rightarrow \mathrm{BALB} / \mathrm{b}$

A. B6BM+B6Siglec- $\mathrm{G}^{-1} \mathrm{~T} \rightarrow \mathrm{BALB} / \mathrm{b}$

H
Non-irradiated model

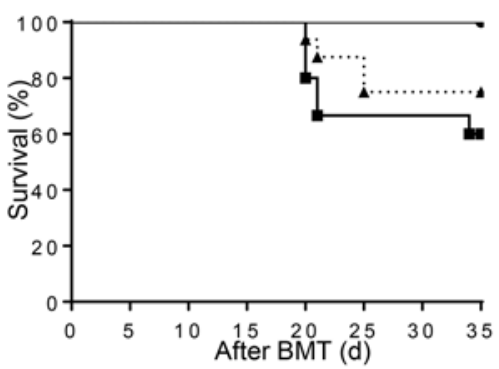

$\rightarrow \mathrm{B} 6 \mathrm{D} 2 \mathrm{~F} 1 \mathrm{BM}+\mathrm{B} 6 \mathrm{D} 2 \mathrm{~F} 1 \mathrm{~T} \rightarrow \mathrm{B} 6 \mathrm{D} 2 \mathrm{~F} 1$

$\rightarrow \mathrm{B} 6 \mathrm{BM}+\mathrm{B} 6 \mathrm{~T} \rightarrow \mathrm{B} 6 \mathrm{D} 2 \mathrm{~F} 1$

- B6BM+B6Siglec- $-\mathrm{G}^{-\mathrm{T}} \rightarrow \mathrm{B} 6 \mathrm{D} 2 \mathrm{~F} 1$
$\mathbf{F}$

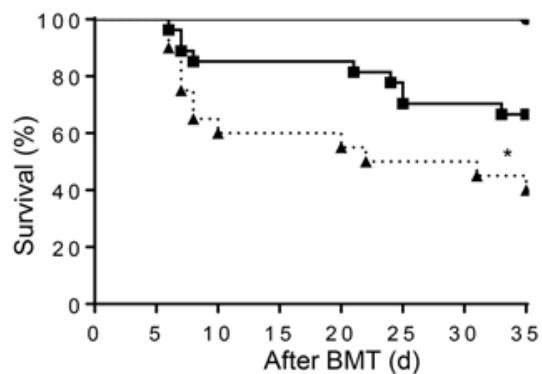

$\rightarrow$ B6D2F1BM+B6D2F1T $\rightarrow$ B6D2F1

- $\mathrm{B} 6 \mathrm{BM}+\mathrm{B} 6 \mathrm{~T} \rightarrow \mathrm{B} 6 \mathrm{D} 2 \mathrm{~F} 1$

.A. B6BM+B6Siglec-G ${ }^{-1-T} \rightarrow$ B6D2F1
G GVHD score (Day 7)



$\mathrm{B} 6 \mathrm{BM}+\mathrm{B} 6 \mathrm{~T} \rightarrow \mathrm{B} 6 \mathrm{D} 2 \mathrm{~F} 1$

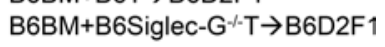


Figure 3. Absence of Siglec-G on donor T cells exacerbates GVHD. (A-E) BALB/c animals received 8.5 Gy on day -1 and were transplanted with $0.75 \times$ $10^{6}$ to $2.0 \times 10^{6} \mathrm{CD} 90.2^{+}$splenic T cells from either syngeneic BALB/C or allogeneic MHC-mismatched B6 WT or B6 Siglec- $\mathrm{C}^{-1-}$ animals along with $5 \times 10^{6}$ T cell-depleted bone marrow (TCD-BM) cells from either BALB/c or B6 donors. (A) Overall survival of allogeneic bone marrow transplantation (allo-BMT) with donor T cells, $0.75 \times 10^{6}\left(n=24-26\right.$ per group). Pooled from 5 independent experiments. (B) Overall survival of allo-BMT with donor T cells, $2 \times 10^{5}(n=$ 5-10 per group). Pooled from 2 independent experiments. Kaplan-Meier method (A and B), ${ }^{*} P<0.05$, when B6 versus Siglec- $\mathbf{C}^{-1-}$ animals were compared. (C and D) Representative figures and histopathological graft-versus-host disease (GVHD) score in liver (C) and gastrointestinal (CI) tracts (small and large intestine) (D) at day 14 after allo-BMT ( $n=5-10$ per group, pooled from 2 experiments). ${ }^{*} P<0.05$ by unpaired $t$ test. (E-C) BALB/b and B6D2F1 animals were used as recipients and received either $8.5 \mathrm{~Gy}$ (BALB/b) or $11 \mathrm{~Gy}$ (B6D2F1) on day -1 and $4 \times 10^{6}$ (BALB/b) and $3 \times 10^{6}$ (B6D2F1) CD90.2 $2^{+}$cells along with $5 \times 10^{6}$ TCD-BM cells from either syngeneic or allogeneic donors. (E) Overall survival in MHC-matched multiple minor antigens-mismatched B6 $\rightarrow B A L B / b$ model. $n=4-10$ per group. Pooled from 2 independent experiments. Kaplan-Meier method, ${ }^{*} P<0.05$ when B6 WT versus B6 Siglec- $\mathrm{C}^{-1-}$ animals were compared. (F and $\mathbf{G}$ ) Overall survival (F) and GVHD clinical score on day 7 (G) in MHC-mismatched haploidentical B6 $\rightarrow$ B6D2F1 model. $n=10-27$ per group. Pooled from 4 independent experiments. Kaplan-Meier method (F), ${ }^{*} P<0.05$. Unpaired $t$ test $(\mathbf{G}),{ }^{* * *} P<0.001$, when B6 WT versus B6 Siglec- $\mathrm{G}^{-1-}$ animals were compared. Data are shown as the mean \pm SEM. (H) Survival of nonirradiated CVHD model. Recipient B6D2F1 animals received $50 \times 10^{6}$ whole splenocytes from either syngeneic B6D2F1 or allogeneic MHC-mismatched B6 WT or B6 Siglec- $\mathrm{G}^{-1-}$ donors. $n=4-16$ per group, pooled from 3 experiments.

determine the magnitude of impact of the absence of Siglec-G on donor T cells on GVHD, we once again utilized the donor-recipient model as above, but this time increased the dose of the donor T cells $\left(2 \times 10^{6}\right)$. While the increase in donor T cells enhanced mortality in WT T recipients, the Siglec-G-deficient donor T cells still showed significantly greater GVHD mortality (Figure 3B). The enhanced mortality of the allogeneic B6-Siglec- $\mathrm{G}^{-/-}$animals was associated with higher serum levels of IFN- $\gamma$ and IL-17 (Figure 2F and Supplemental Figure 6C), as well as more severe GVHD-specific histopathological damage of the target organs liver, GI tract, and lungs (Figure 3, C and D, and Supplemental Figure 6D). To eliminate straindependent factors, we utilized other BMT models wherein DAMPs are released as a consequence of conditioning by irradiation, namely the MHC-matched but multiple minor antigen-mismatched $\mathrm{B} 6 \rightarrow \mathrm{BALB} / \mathrm{b}$ and the haploidentical $\mathrm{B} 6 \rightarrow \mathrm{B} 6 \mathrm{D} 2 \mathrm{~F} 1$ models. In all of these multiple systems, the allorecipients that received $\mathrm{B} 6$ Siglec $-\mathrm{G}^{-/-} \mathrm{T}$ cells demonstrated significantly worse GVHD mortality and histopathological damage than those that received T cells from B6 WT animals (Figure 3, E-G).

Next, to confirm in vivo that the effect of Siglec-G on T cells following their TCR stimulation was relevant only in the presence of DAMPs, we next utilized the nonirradiated (i.e., absence of condition-related damage and DAMP release) $\mathrm{B} 6 \rightarrow \mathrm{B} 6 \mathrm{D} 2 \mathrm{~F} 1 \mathrm{BMT}$ model. In contrast to the irradiated allo-BMT models, the allogeneic Siglec- $\mathrm{G}^{-/-}$animals demonstrated a similar mortality when compared with WT controls (Figure $3 \mathrm{H}$ ).

Siglec-G does not alter Treg-mediated suppression. We next explored potential mechanisms. It is possible that absence of Siglec-G might reduce Treg-intrinsic functions, leading to enhanced responses of conventional naive $\mathrm{T}$ cell responses. Therefore, we explored whether the enhanced conventional naive $\mathrm{T}$ cell function was dependent on Tregs. As shown in Figure 4A, the in vitro functions of WT and Siglec- $\mathrm{G}^{-{ }^{-}}$Tregs were equivalent in limiting proliferation of WT or Siglec- $\mathrm{G}^{-/-}$naive T cells, suggesting that Siglec-G expression is not critical for their suppressive function. Consistent with these in vitro observations, the allogeneic recipients that received Siglec- $\mathrm{G}^{-/-}$donor $\mathrm{T}$ cells demonstrated a significantly greater mortality than those that received WT $\mathrm{T}$ cells even when the $\mathrm{CD} 4^{+} \mathrm{CD} 25^{+} \mathrm{T}$ cells were depleted from the donor inoculum (Figure 4B). These data demonstrate that the enhanced response of Siglec-G-deficient naive $\mathrm{T}$ cells is not because of loss of Treg suppressive functions.

Interaction of Siglec-G on T cells with CD24 is critical for repressing DAMP-mediated amplification of their responses. To further dissect potential mechanisms, we next focused on the APC-Siglec-G interaction because CD24 directly binds a broad range of DAMPs, and also binds to Siglec-G and then represses the responses to DAMPs $(7,8,21)$. We hypothesized that if the APC CD24 interaction with donor T cell Siglec-G is critical, then the absence of CD24 on host APCs would enhance GVHD. Consistent with this hypothesis, the CD24-/ APCs demonstrated a significantly greater capacity for stimulation of allogeneic WT T cells than WT APCs (Figure $5 \mathrm{~A})$. We next examined the functional relevance of the CD24-Siglec-G interaction during the development of GVHD in vivo and found that, as hypothesized, allogeneic $\mathrm{CD} 24^{-/-}$animals demonstrated a significantly greater mortality than allogeneic WT controls (Figure $5 \mathrm{~B}$ ) in the $\mathrm{B} 6 \rightarrow \mathrm{BALB} / \mathrm{c}$ model.

Siglec-G agonist mitigates GVHD. Next, to confirm that the interaction between Siglec-G on donor T cells and CD24 on host cells is critical for controlling GVHD, we utilized a novel CD24Fc fusion protein that consists of the extracellular domain of mature human CD24 linked to the human immunoglobulin G1 (IgG1) Fc domain (7) and serves as a direct agonist to Siglec-G, to enhance the CD24-Siglec-G interaction (7). We treated the recipients with $\mathrm{CD} 24 \mathrm{Fc}$ on day $0(5 \mathrm{mg} / \mathrm{kg})$ in the $\mathrm{B} 6 \rightarrow \mathrm{BALB} / \mathrm{c}$ model. Consistent with a previous report (18), we found that B6 WT animals treated with CD24Fc showed a significant amelioration of GVHD 
A

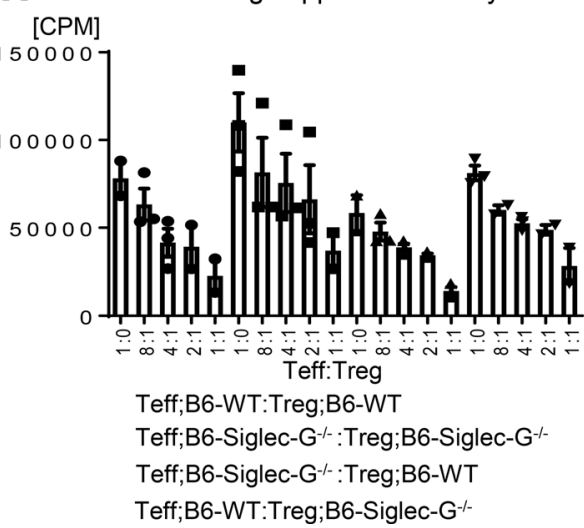

Figure 4. Siglec-G does not alter Treg-mediated suppression. (A) Treg suppression assay. Bone marrow-derived DCs from BALB/c mice were used as stimulators, cocultured with effector T cells $\left(\mathrm{CD}^{+} \mathrm{CD} 25^{-}\right)$and Tregs $\left(\mathrm{CD} 4^{+} \mathrm{CD} 25^{+}\right)$from either B6 WT or B6 Siglec $-\mathrm{C}^{-1-}$ animals at different ratios in a mixed lymphocyte reaction (MLR) and analyzed for $\mathrm{T}$ cell proliferation following ${ }^{3} \mathrm{H}$-thymidine incorporation during the last 16 hours of incubation $(P=$ not significant [NS]). (B) Survival of WT BALB/c animals in Treg-depleted allogeneic bone marrow transplantation (allo-BMT). Recipient BALB/C animals received 8.5 Gy on day -1 and were transplanted with splenic CD25-depleted T cells along with $T$ cell-depleted bone marrow from either syngeneic BALB/c or allogeneic MHCmismatched B6 donors. $n=4-16$ per group, pooled from 3 experiments. Kaplan-Meier method.

${ }^{* *} P<0.01$, when B6 WT versus B6 Siglec $-\mathrm{C}^{-1-}$ animals were compared.
(Supplemental Figure 7, A and B). We next confirmed that $\mathrm{CD} 24 \mathrm{Fc}$ was stimulating Siglec$G$ and enhanced the negative ITIM signaling pathway. When allogeneic WT donor T cells were harvested on day 7 after treatment with CD24Fc and BMT, the p-SHP-1 was enhanced only in the donor $\mathrm{T}$ cells from the animals that were treated with the $\mathrm{CD} 24 \mathrm{Fc}$ fusion protein (Figure 5C and Supplemental Figure 8).

Next, to further confirm the specificity of the interaction of CD24Fc with Siglec-G, we lethally irradiated and transplanted the $\mathrm{BALB} / \mathrm{c} \mathrm{CD} 24^{-/-}$animals with $\mathrm{T}$ cells from either B6 WT or B6 Siglec- $\mathrm{G}^{-/-}$animals, which disrupted the interaction between Siglec-G and $\mathrm{CD} 24$. Administration of the $\mathrm{CD} 24 \mathrm{Fc}$ significantly reduced GVHD in the animals that received T cells from B6 WT (Figure 5D) but not B6 Siglec- $\mathrm{G}^{-/}$animals (Figure 5E). Furthermore, administration of $\mathrm{CD} 24 \mathrm{Fc}$ still significantly ameliorated GVHD in the absence of CD24 in both APCs and T cells (but had intact Siglec-G) (Figure 5F). These data collectively demonstrate that engagement of Siglec-

G on donor T cells by CD24Fc controls DAMP-mediated aggravation of GVHD (Supplemental Table 1).

We next determined the putative translational potential of this approach to clinical allo-BMT following myeloablative conditioning. To this end, we next explored whether $\mathrm{CD} 24 \mathrm{Fc}$ adds value as an adjuvant to the currently used clinical immune prophylaxis in humans, the calcineurin inhibitor tacrolimus. When $\mathrm{CD} 24 \mathrm{Fc}$ was administered as above, along with daily treatment of tacrolimus, addition of CD24Fc significantly improved GVHD severity and mortality (Figure 5G).

Effect of enhancing Siglec-G responses with CD24Fc on GVT responses. Because GVHD is tightly linked with the graft-versus-tumor (GVT) effect and HMBG-1 released from necrotic or dying cancer cells is critical for the activation of tumor antigen-specific $\mathrm{T}$ cells (22), we next explored whether decreasing donor $\mathrm{T}$ cell responses to DAMPs by enhancing the Siglec-G-CD24 interaction substantially altered the GVT responses. We utilized the same model of CD24Fc treatment as above, but added P815 at the time of BMT. Interestingly, CD24Fc-treated animals showed equivalent GVT response to nontreated animals (Figure 6, A-C). Similar GVT responses were also observed at a higher dose $\left(5 \times 10^{2} /\right.$ mouse) (Figure $\left.6 \mathrm{D}\right)$ and in a second tumor model (A20 tumor cells) (Figure $6 \mathrm{E}$ ). In addition, $\mathrm{T}$ cells isolated from $\mathrm{CD} 24 \mathrm{Fc}$-treated animals as well as nontreated animals showed equivalent killing of allogeneic $\mathrm{P} 815$ tumors in an ex vivo $\mathrm{T}$ cell cytotoxic killing assay (Figure 6F).

Taken together, these data demonstrate that the administration of CD24Fc mitigates GVHD while maintaining a sufficient GVT effect in these models. It is, however, important to note that these data still do not demonstrate whether the magnitude of GVT effects may be compromised, especially in instances where the tumors are less immunogenic or more rapidly proliferating.

Siglec-10 is expressed by human $T$ cells and controls in vitro responses. To demonstrate potential human clinical relevance of enhancement of the Siglec-G-CD24 interaction as a strategy to mitigate GVHD that is aggravated by GVHD, we explored whether human T cells expressed the ortholog of Siglec$\mathrm{G}$, namely Siglec-10 (23). The naive $\mathrm{CD}^{+} \mathrm{T}$ cells from human peripheral blood mononuclear cells (PBMCs) expressed Siglec-10 on $3.3 \% \pm 2.5 \%$ of total $\mathrm{T}$ cells (Figure $7 \mathrm{~A}$ ). Interestingly, CD24Fc dramatically decreased the nonspecific TCR responses when PBMCs were incubated either during or before with HMBG-1 (Figure 7B). However, reduced nonspecific TCR responses with HMBG-1 were completely eliminated when Siglec-10-depleted PBMCs were used (Figure 7C), suggesting that Siglec-10, the human ortholog of murine Siglec-G, has similar effects on $\mathrm{T}$ cell responses only in the presence of DAMPs. These data nonetheless do not indicate the relevance of Siglec-10 in the absence of DAMPs or its relevance in comparison with other T cell checkpoint molecules. 
A

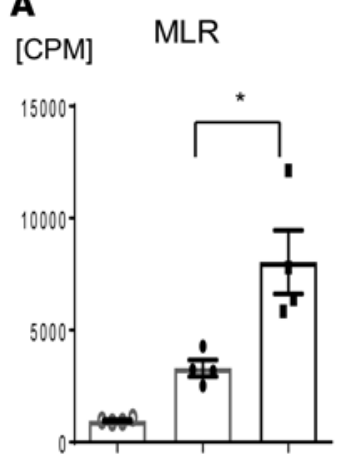

- Syngeneic APCs

- Allogeneic B6WT APCs

- Allogeneic B6CD24-/B6 APCs

B

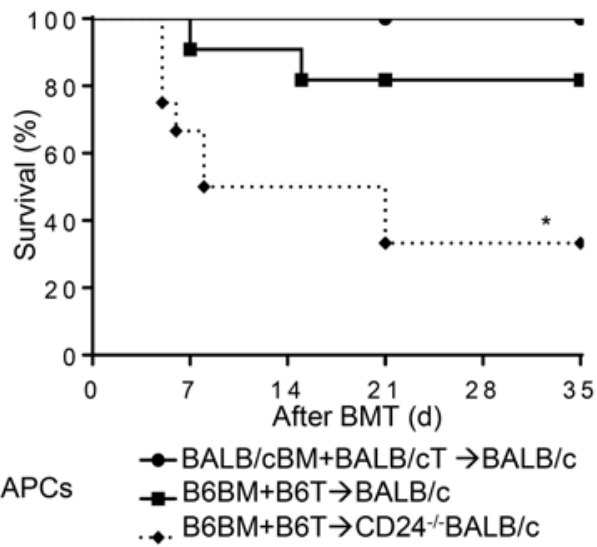

C

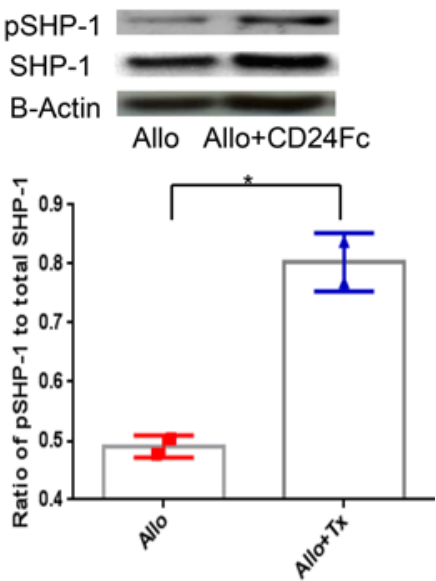

pSHP-1/SHP-1
D



$\rightarrow$ BALB/cBM+BALB/cT $\rightarrow$ BALB/cCD24

$\rightarrow \mathrm{B} 6 \mathrm{BM}+\mathrm{B} 6 \mathrm{~T} \rightarrow \mathrm{BALB} / \mathrm{cCD} 24^{-}$

$\rightarrow$ B $6 \mathrm{BM}+\mathrm{B} 6 \mathrm{~T} \rightarrow \mathrm{BALB} / \mathrm{CCD} 24^{--+\mathrm{CD}} 24 \mathrm{FC}$

F

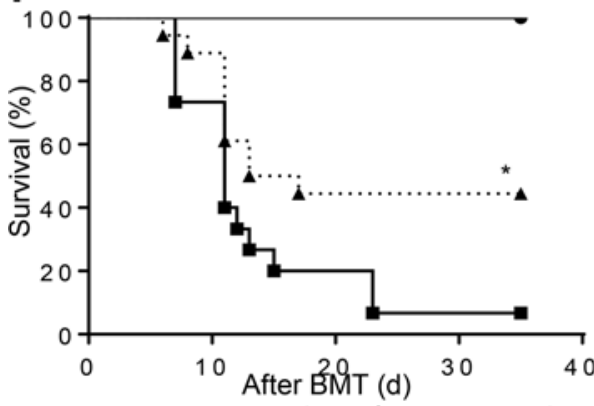

BALB/cCD24 $4^{-/} \mathrm{BM}+\mathrm{BALB} / \mathrm{cCD} 24^{-/-T}$ $\rightarrow \mathrm{BALB} / \mathrm{CCD} 24^{-/}$

$\rightarrow \mathrm{B} 6 \mathrm{CD} 24^{-/} \mathrm{BM}+\mathrm{B} 6 \mathrm{CD} 24^{-1-\mathrm{B} 6 \mathrm{~T}}$ $\rightarrow \mathrm{BALB} / \mathrm{cCD} 24^{-/}$

... B BCD24 ${ }^{-/} \mathrm{BM}+\mathrm{B} 6 \mathrm{CD} 24 \%$

$\rightarrow \mathrm{BALB} / \mathrm{cCD} 24^{-/-}+\mathrm{CD} 24 \mathrm{Fc}$

G
E

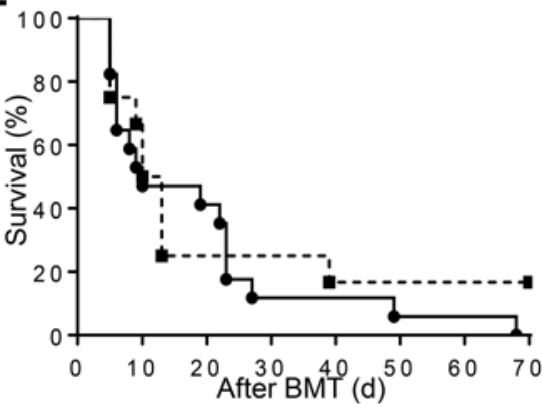

- B6BM+B6Siglec- ${ }^{-1}-\mathrm{T}^{-} \rightarrow \mathrm{BALB} / \mathrm{cCD} 24^{-1}$

- - B6BM+B6Siglec-G ${ }^{-}-\mathrm{T} \rightarrow \mathrm{BALB} / \mathrm{CCD} 24^{-/}$ $+\mathrm{CD} 24 \mathrm{Fc}$



Figure 5. Siglec-G-CD24 interaction regulates DAMP-mediated donor T cell responses and enhancement of Siglec-G/CD24 axis mitigates GVHD. (A) Isolated CD90.2+ T cells from B6 WT were cultured with irradiated splenocytes from B6 WT, BALB/C WT or CD24 ${ }^{-/-}$BALB/C animals for 72 hours in a mixed lymphocyte reaction (MLR) and analyzed for proliferation following ${ }^{3} \mathrm{H}$-thymidine incorporation during the last 6 hours of incubation. Unpaired $t$ test. Data are shown as the mean \pm SEM of quadruplicate cultures and are representative from 1 of 3 similar experiments. ${ }^{*} P<0.05$ when B6 WT versus B6 CD24-/- antigen-presenting cells were compared. (B) Overall survival. Recipient BALB/C WT or BALB/C CD24 ${ }^{-/-}$animals received 8.5 Gy on day -1 and were transplanted with splenic T cells along with T cell-depleted bone marrow (TCD-BM) cells from either syngeneic BALB/C or allogeneic MHCmismatched B6 donors. $n=6-12$ per group, pooled from 3 experiments. Kaplan-Meier method, ${ }^{*} P<0.05$ when BALB/c WT versus BALB/c CD24 ${ }^{-/-}$recipients were compared. (C) CD24Fc treatment increased phosphorylated (p) and total of SHP-1. Upper: A representative figure of immunoblot analysis of p-SHP-1 and total SHP-1 protein in lysates of donor T cells from untreated and treated animals at day 7 after allogeneic bone marrow transplantation (allo-BMT). Lower: The bar graph shows the ratio $p-S H P-1 /$ total SHP-1. Mann-Whitney $U$ test, ${ }^{*} P<0.05$. (D-F) BALB/c CD24 ${ }^{-1-}$ animals were lethally irradiated with 8.5 Gy and infused with $0.75 \times 10^{6}$ CD90.2+ T cells along with $5 \times 10^{6}$ TCD-BM cells from allogeneic MHC-mismatched B6 donors (D) or B6 Siglec $-\mathrm{C}^{-1-}$ donors (E) or B6 CD24-/- donors (F). The recipients were injected with CD24Fc or diluent control on day 0 before allo-BMT. Kaplan-Meier method, ${ }^{*} P<0.05$, when control diluent versus CD24Fc treatment animals were compared. $n=4-18$ per group, pooled from 2 experiments. (G) Aug- 
menting Siglec- $\mathrm{G}$ with CD24Fc improves tacrolimus-induced protection of experimental graft-versus-host disease (GVHD). BALB/c WT animals were lethally irradiated with 8.5 Gy and infused with $0.75 \times 10^{6} \mathrm{CD} 90^{+}$T cells along with $5 \times 10^{6}$ TCD-BM cells from either syngeneic BALB/c WT or allogeneic MHC-mismatched B6 donors. The recipients were injected with CD24Fc $(5 \mathrm{mg} / \mathrm{kg})$ or diluent control on day 0 and treated with tacrolimus $(0.005 \mathrm{mg} /$ $\mathrm{kg}$, i.p.) for 14 days. $n=6-15$ per group, pooled from 3 experiments. Kaplan-Meier method, ${ }^{* *} P<0.01$, when control versus CD24Fc plus tacrolimus treatment group and ${ }^{*} P<0.05$, when tacrolimus versus CD24Fc treatment groups were compared.

\section{Discussion}

Most investigations exploring the functions and impact of DAMPs have focused on the innate arm of the immune responses. Those that focused on negative regulatory effects of Siglecs focused only on innate immunity or on B cell-intrinsic functions $(3,6,24,25)$. However, the roles of DAMPs and Siglecs in T cell biology remain unexplored. Our data collectively demonstrate for the first time, to our knowledge, that $\mathrm{T}$ cell responses in the presence of DAMPs can be repressed by Siglec-G in a cell-autonomous manner. This direct repression of enhanced $\mathrm{T}$ cell responses in the presence of DAMPs can be targeted to mitigate the $\mathrm{T}$ cell-mediated in vivo immunopathology, GVHD. This effect was at least in part dependent on the interaction of Siglec-G on T cells with CD24-expressing APCs. These data extend previous observations of the role of the CD24-Siglec axis on host APCs in the biology of GVHD. CD24 is broadly expressed in hematopoietically derived cells, immature neuronal cells, and epithelial cells (26). Given the complexity and number of cell types involved in inducing and amplifying GVHD, whether Siglec expression on donor or host B cells or other cells will affect acute GVHD remains to be explored $(27,28)$.

CD24 is reported to be expressed in solid tumors (29) and associated with tumor growth and metastasis $(30,31)$ caused by p53 inactivation (32). Therefore, CD24 stimulation might potentially increase the risk of relapse and cause unexpected toxicities. However, our data demonstrate that enhancing Siglec-G responses with CD24Fc, a novel clinical grade fusion protein, mitigated GVHD but retained sufficient GVT responses. Additionally, CD24Fc enhanced GVHD reduction even in animals receiving calcineurin inhibitors, suggesting that this could be a novel approach as an adjunct to current clinical practice. The GVT models, while useful, are not entirely reflective of clinical situations and have model-specific limitations. We also demonstrate that Siglec-10, an ortholog of Siglec-G, is expressed on a subset of human $\mathrm{T}$ cells that plays an important role in prevention of enhancement of $\mathrm{T}$ cell responses by DAMPs. Nonetheless, when taken collectively our data suggest that addition of CD24Fc targeting the DAMP-dependent T cell responses could be a novel strategy to mitigate GVHD that could be explored in carefully designed clinical trials.

Both PAMPs and DAMPs amplify GVHD, but Siglec-G specifically appears to repress only DAMPmediated amplification of $\mathrm{T}$ cell responses, consistent with observations of Siglec- $\mathrm{G}$ on repressing DAMP-specific responses of innate immune cells (18). Thus, targeting Siglec-G/CD24 pathways may be selective against DAMP-mediated inflammation that amplifies effector $\mathrm{T}$ cell responses. Furthermore, because the CD24-Siglec-G interaction has only been associated with regulating DAMP but not PAMP responses, it is tempting to speculate that the utilization of CD24Fc in the context of allogeneic hematopoietic cell transplantation (allo-HCT) may not increase infectious complications while reducing DAMP-associated aggravation of GVHD. Thus, Siglec-G has T cell-autonomous effects in repressing DAMP-mediated amplification of their responses. When taken together with our previous observations (18), these data show that Siglec-G is an important regulator of inflammatory responses to tissue injuries, and these results provide a strong rationale for targeting negative regulatory pathways such as the Siglec-G/CD24 axis as a strategy for reducing GVHD.

\section{Methods}

Mice. C57BL/6 (B6, H-2 $\left.2^{\mathrm{b}}, \mathrm{CD} 45.2^{+}\right)$, B6D2F1 (H-2 $\left.2^{\mathrm{b}}\right)$, C3H.sw $\left(\mathrm{H}-2^{\mathrm{b}}\right)$, and BALB/b $\left(\mathrm{H}-2^{\mathrm{b}}\right)$ mice were purchased from the Jackson Laboratory. BALB/c $\left(\mathrm{H}-2^{\mathrm{d}}\right)$ mice were purchased from Charles River Laboratories. B6 Ly5.2 (H-2 $2^{\mathrm{b}}$ CD45.1 $\left.{ }^{+}\right)$mice were purchased from NCI-Frederick. B6-background Siglec$\mathrm{G}^{-/-} \mathrm{GFP}^{+/+}$and $\mathrm{CD} 24^{-/-}$have been described previously $(5,33)$ and were provided by Pang Zheng and Chen Liu (Children's National Medical Center). To make BALB/c CD24 ${ }^{-/-}$animals, the CD24-null allele was backcrossed to the BALB/c background by marker-assisted speed breeding for 5 generations to eliminate all B6-specific genetic markers. All animals were cared for according to regulations reviewed and approved by the University Committee on Use and Care of Animals of the University of Michigan, based on University Laboratory Animal Medicine guidelines. 
A

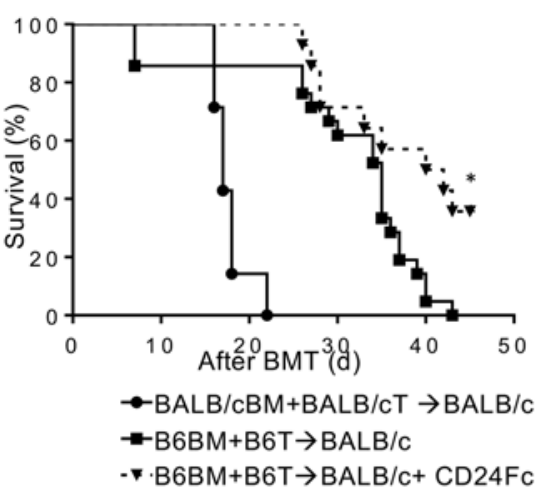

B



C

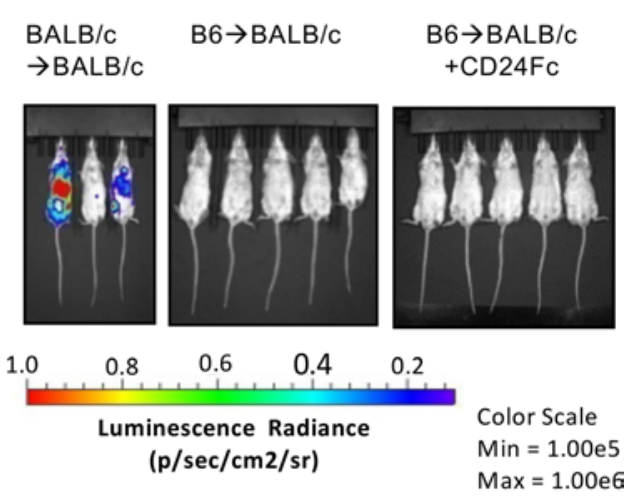

D

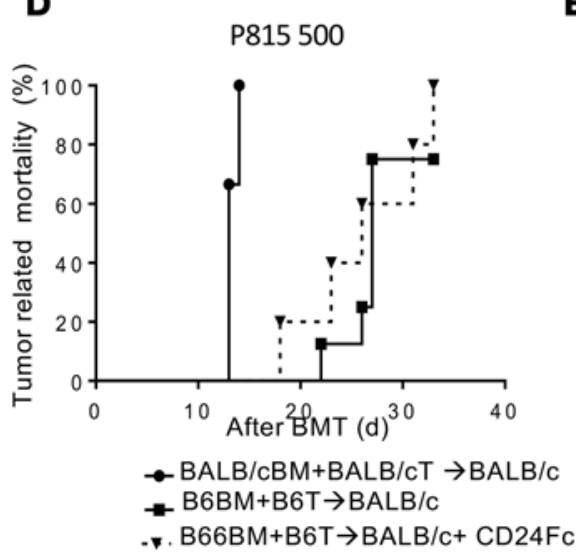

E

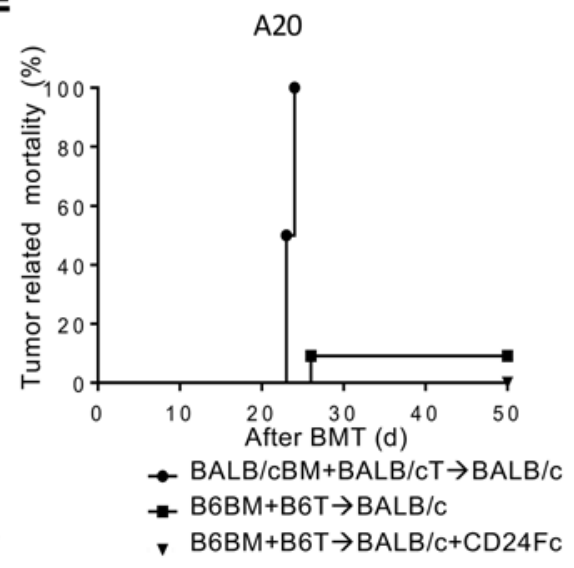

$\mathbf{F}$ ${ }^{51} \mathrm{Cr}$ release assay

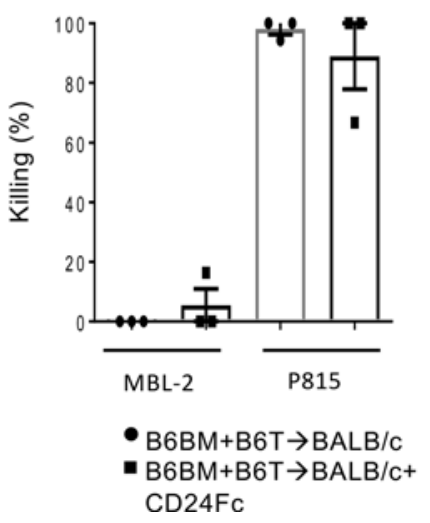

Figure 6. Effect of enhancing Siglec-G responses with CD24Fc on graft-versus-tumor (GVT) responses. BALB/c animals were lethally irradiated with $8.5 \mathrm{~Gy}$ and infused with $0.75 \times 10^{6} \mathrm{CD}^{+} \mathrm{T}$ cells along with $5 \times 10^{6} \mathrm{~T}$ cell-depleted bone marrow (TCD-BM) cells from either syngeneic BALB/c or allogeneic MHC-mismatched B6 donors concurrently with syngeneic $1 \times 10^{2}$ P815 tumors simultaneously with allogeneic hematopoietic cell transplantation (allo-HCT). The recipients were injected with CD24Fc or diluent control on day 0 before allogeneic bone marrow transplantation (allo-BMT). (A) Overall survival. Kaplan-Meier method, ${ }^{* *} P<0.01$ when control diluent versus CD24Fc treatment animals were compared. (B) Tumor-related mortality. $n=7-21$ per group, pooled from 3 experiments. (C) Tumor growth was monitored using bioluminescence imaging (BLI) at day 14 after allo-HCT ( $n$ $=2-5$ ). Representative data from 3 independent experiments are shown. (D) Tumor-related mortality data of P815, $5 \times 10^{2} /$ mouse $(n=3-8$ per group), pooled from 2 experiments. (E) Tumor-related mortality of $A 20,1 \times 10^{5} /$ mouse. $n=4-11$ per group, pooled from 2 experiments. (F) ${ }^{51} \mathrm{Cr}$-release assay using donor CD8 ${ }^{+}$T cells at day 14 after allo-HCT against MBL-2 (syngeneic) and P815 (allogeneic) tumors. Representative data from 3 independent experiments are shown. Data are shown as the mean \pm SEM.

$B M T$. BMTs were performed as previously described $(18,34,35)$. Briefly, splenic $\mathrm{T}$ cells from donors were enriched, and the BM was depleted of T cells by autoMACS (Miltenyi Biotec) utilizing CD90.2 microbeads (Miltenyi Biotec). We used well-established multiple BMT models. BALB/c, B6D2F1, C3H.sw, and BALB.B-WT animals were used as recipients and received either 8.5 Gy (BALB/c and BALB.B), 10.5 Gy (C3H.sw), or $11 \mathrm{~Gy}(\mathrm{~B} 6 \mathrm{D} 2 \mathrm{~F} 1)\left({ }^{137} \mathrm{Cs}\right.$ source) on day -1 and 0.75 $\times 10^{6}(\mathrm{~B} 6 \rightarrow \mathrm{BALB} / \mathrm{c}), 1 \times 10^{6}(\mathrm{~B} 6 \rightarrow \mathrm{C} 3 \mathrm{H} . \mathrm{sw}), 3 \times 10^{6}(\mathrm{~B} 6 \rightarrow \mathrm{B} 6 \mathrm{D} 2 \mathrm{~F} 1)$, and $4 \times 10^{6}(\mathrm{~B} 6 \rightarrow \mathrm{BALB} . \mathrm{B})$ $\mathrm{CD} 90.2^{+} \mathrm{T}$ cells along with $5 \times 10^{6} \mathrm{TCD}-\mathrm{BM}$ cells from either syngeneic or allogeneic donors. In a Treg-depleted BMT model, $\mathrm{T}$ cells were isolated from spleen and purified utilizing a Pan-T Cell Isolation Kit (Miltenyi Biotec). Isolated T cells were incubated with CD25 microbeads (Miltenyi Biotec) and depleted on a magnetic column. BALB/c animals received $1 \times 10^{6} \mathrm{CD} 25^{-/-} \mathrm{T}$ cells along with $5 \times$ $10^{6} \mathrm{TCD}-\mathrm{BM}$ on day 0 . In the nonirradiated BMT model, recipient B6D2F1 animals received $50 \times 10^{6}$ splenocytes from syngeneic B6D2F1, allogeneic B6 WT, or Siglec- $\mathrm{G}^{-/-}$animals on day 0 .

Systemic and histopathological analysis of GVHD. We monitored survival after allo-HCT daily and assessed the degree of clinical GVHD weekly, as described previously (36). Histopathological analysis of the liver, GI tract, and lung, which are the primary GVHD target organs, was performed as previ- 
A

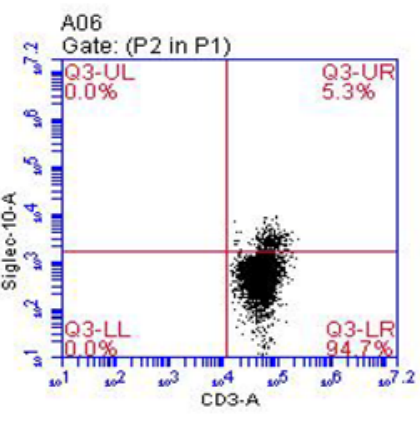

B

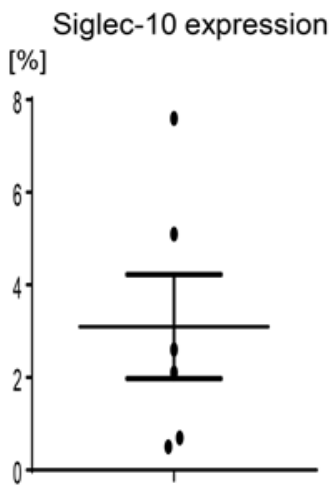

Whole PBMCs
CD3/CD28 w HMGB-1

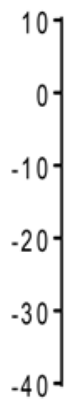

Pre-treated HMGB-1 and $\mathrm{CD} 3 / \mathrm{CD} 28$
No Tx

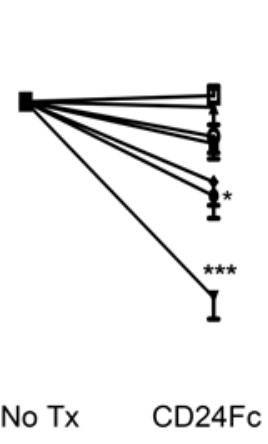

Siglec-10 depleted PBMCs
CD3/CD28 w HMGB-1
Pre-treated HMGB-1 and $\mathrm{CD} 3 / \mathrm{CD} 28$

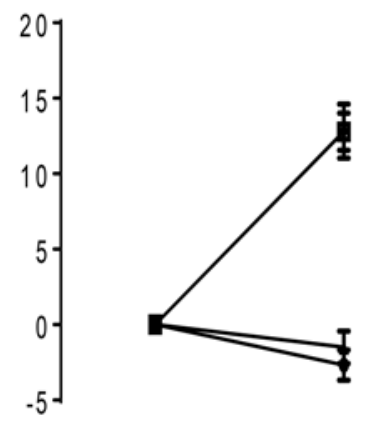

No Tx CD24Fc

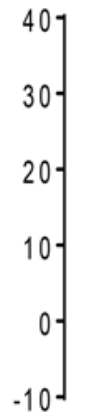

$-10$

\section{and $\mathrm{CD} 3 / \mathrm{CD} 28$}

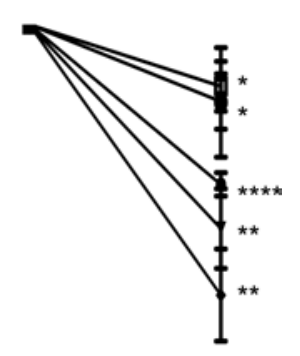

No Tx

$\mathrm{CD} 24 \mathrm{Fc}$

Figure 7. CD24Fc ameliorates nonspecific TCR responses, particularly in the case of those prestimulated with HMGB-1 in human PBMCs in vitro. Human peripheral blood mononuclear cells (PBMCs) were isolated with Ficoll and cultured on anti-CD3 mAb-precoated dishes along with antiCD28 mAb and HMCB-1 for 48 and 72 hours. Cells were harvested and stained for human CD3 and Siglec-10. (A) Left: A representative FACS plot of Siglec-10 expression in $\mathrm{CDB}^{+}$T cells. Right: Siglec-10 expression in naive CD3 ${ }^{+}$T cells of PBMCs $(n=7)$. (B) Proliferation of PBMCs incubated with anti-CD3 and anti-CD28 mAbs in the presence or absence of HMGB-1 with CD24Fc for 48 hours and analyzed for proliferation following ${ }^{3} \mathrm{H}$-thymidine incorporation during the last 6 hours of incubation. Paired analysis of CD24Fc treatment of human PBMCs is shown. Left: Anti-CD3/CD28 stimulation along with HMGB-1 $(n=7)$. Right: Pretreated with HMGB-1 and anti-CD3/CD28 stimulation $(n=6)$. Paired $t$ test, ${ }^{*} P<0.05,{ }^{* *} P<0.02,{ }^{* *} P<0.01$, ${ }^{* * * *} P<0.002$ showed significant reduction between nontreatment and CD24Fc treatment. (C) Human Siglec-10-depleted PBMCs were isolated with Ficoll and MACS and cultured on anti-CD3 mAb-precoated dishes along with anti-CD28 mAb and HMCB-1 for 48 hours and analyzed for proliferation following ${ }^{3} \mathrm{H}$-thymidine incorporation during the last 6 hours of incubation. Paired analysis in CD24Fc treatment of human PBMCs is shown. Left: Anti-CD3/CD28 stimulation along with HMGB-1 $(n=7)$. Right: Pretreated with HMGB-1 and anti-CD3/CD28 stimulation $(n=6)$. No Tx, no treatment.

ously described (37) utilizing a semiquantitative scoring system implemented by a single pathologist (Chen Liu) (37). After scoring, the codes were broken, and the data were compiled.

$D C$ cultures. To obtain DCs, BM cells from B6 WT or BALB/c WT were cultured with murine recombinant GM-CSF (20 ng/ml; PeproTech) for 7 days and harvested as described previously (38). DCs were isolated by using CD11c (N418) MicroBeads (Miltenyi Biotec) and the autoMACS and utilized as stimulator for the mixed lymphocyte reaction (MLR) and Treg suppression assay.

FACS analysis. FACS analyses were performed as previously described $(38,39)$. Briefly, to analyze donor $\mathrm{T}$ cell expansion and activation markers, splenocytes from transplant-recipient mice were resuspended in FACS wash buffer (2\% BSA in PBS) and stained with the following conjugated mAbs: PerCP-Cy5.5-conjugated mAbs against mouse CD4 (clone GK1.5) and CD8 (clone 53-6.7); PE-conjugated mAbs against mouse CD69 (clone H1.2F3), CD183 (CXCR3) (clone CXCR3-173), LPAM-1 (integrin $\alpha 437$ ) (clone DATK32), CD62L (clone MEL-14), and TIGIT (clone 1G9); APC-conjugated mAbs against mouse H-2K (clone AF6-88.5), CD44 (clone IM7), PD-1 (clone 29F.1A12), and Lag3 
(clone C9B7W) (Biolegend). For Siglec-G expression in B6 WT mice, we utilized APC-conjugated mAbs against mouse Siglec-G (clone SH2.1, eBioscience) and FITC-conjugated mAbs against mouse CD3 (clone 17A2, Biolegend). After staining, the cells were washed twice and fixed with $2 \%$ formaldehyde. The procedure was performed as described previously (38). Cells were analyzed using a BD Accuri C6 flow cytometer (BD Bioscience) or Attune NxT flow cytometer (Thromo Fisher Scientific). For intracellular staining to detect cytokines, cells were permeabilized after fixation and stained with PE-conjugated anti-IFN- $\gamma$ (clone XMG1.2) and anti-Foxp3 (clone MF-14) (both Biolegend) according to the manufacturer's protocol. The list of antibodies is summarized in Supplemental Table 2.

MLR. Splenic T cells from B6 and Siglec-G ${ }^{-/-}$animals (magnetically separated by MACS using CD90.2 microbeads) were used as responders and BALB/c WT- versus B6 WT-derived BMDCs were used as stimulators in an MLR. T cells $\left(1 \times 10^{5}\right)$ and irradiated $(20 \mathrm{~Gy})$ BMDCs $\left(2.5 \times 10^{3}\right)$ were cocultured on 96 -well roundbottom plates for 96 hours. The incorporation of ${ }^{3} \mathrm{H}$-thymidine $(1 \mu \mathrm{Ci} /$ well $)$ by proliferating $\mathrm{T}$ cells during the final 16 hours of coculture was measured by a Betaplate reader (Wallad). In using splenocytes as stimulators, 4 $\times 10^{5} \mathrm{~T}$ cells from BALB/c WT animals and $1 \times 10^{5}$ irradiated (30 Gy) red blood cell-lysed splenocytes from $\mathrm{BALB} / \mathrm{c}$ WT, B6 WT, and B6 CD24 $4^{--}$animals were cocultured on 96-well flat-bottom plates for 72 hours and analyzed for proliferation following ${ }^{3} \mathrm{H}$-thymidine incorporation during the last 6 hours of incubation.

Nonspecific TCR stimulation. Isolated T cells $\left(1 \times 10^{5} /\right.$ well $)$ were stimulated with anti-CD3 $(2 \mu \mathrm{g} / \mathrm{ml}$, clone 154-2C11, Biolegend) and CD28 (1 $\mathrm{g} / \mathrm{ml}$, clone 37.51, Biolegend) antibodies on 96-well roundbottom plates in the absence or presence of HMBG-1 $(10 \mu \mathrm{g} / \mathrm{ml}$, eBioscience) for 24 or 48 hours. The incorporation of ${ }^{3} \mathrm{H}$-thymidine $(1 \mu \mathrm{Ci}$ /well) by proliferating $\mathrm{T}$ cells during the final 6 hours of culture was measured by a Betaplate reader (Wallad).

Treg suppression assay. $\mathrm{CD} 4{ }^{+} \mathrm{CD} 25^{-}$and $\mathrm{CD} 4^{+} \mathrm{CD} 25^{+} \mathrm{T}$ cells were isolated from the spleen from WT B6 or Siglec-G ${ }^{-/-}$animals using a $\mathrm{CD} 4{ }^{+} \mathrm{CD} 25^{+}$Regulatory $\mathrm{T}$ Cell Isolation Kit (Miltenyi Biotec) with MACS according to the manufacturer's protocol. The purity of each cell type was greater than $90 \%$. $\mathrm{CD} 4^{+} \mathrm{CD} 25^{+} \mathrm{T}$ cells were serially diluted from $2 \times 10^{4}$ to 2,500 cells/well and incubated with $2 \times 10^{4}$ $\mathrm{CD}^{+} \mathrm{CD} 25^{-} \mathrm{T}$ cells and $5 \times 10^{3}$ irradiated BALB/c-derived BMDCs for 120 hours. Incorporation of ${ }^{3} \mathrm{H}$-thymidine $(1 \mu \mathrm{Ci} /$ well) by proliferating cells was measured during the last 18 hours of culture.

$R N A$ isolation and RT-PCR. Total cellular RNA was isolated using a miRNeasy Kit (Qiagen) and then reverse transcribed (500 ng RNA) using a High Capacity cDNA Reverse Transcription Kit( Applied Biosystems) in a total volume of $40 \mu 1$. A $0.5-\mu 1$ aliquot of the reverse transcription (RT) reaction was analyzed by PCR using primer pairs specific for Siglec-G (5'-TCCAGTGGCCACAAATAACA-3' and 5'-TCTGAGTCAGGGCTTCCACT-3'), and glyceraldehyde-3-phosphate dehydrogenase (5'-AAATCCCATCACCATCTTCC-3' and 5'-GTCCACCACCCTGTTGCTGC-3'). PCR products were resolved in 1\% agarose ethidium bromide gels and bands were visualized on an AlphaImager HP System (Proteinsimple) and images were inverted for presentation to show dark bands on a light background.

$T$ cell competition study. BALB/c WT were lethally irradiated with $8.5 \mathrm{~Gy}$ on day -1 and received $1 \times$ $10^{6} \mathrm{~T}$ cells from CD45.1 $1^{+}$B6 Ly5.2 and $1 \times 10^{6} \mathrm{~T}$ cells from CD45.2 $2^{+}$Siglec-G ${ }^{-/}$animals on day 0 . On day 4 after transfer, spleens were isolated and stained with PE-conjugated $\mathrm{mAbs}$ against mouse CD45.1 (clone A20, Biolegend), APC-conjugated mAbs against mouse H-2K $\mathrm{K}^{\mathrm{b}}$, and PerCP-Cy5.5-conjugated mAbs against mouse CD45.2 (clone 104, Biolegend).

Cytokine enzyme-linked immunosorbent assay (ELISA). Concentrations of IFN- $\gamma$ and IL-17A were measured in the serum and culture supernatants by ELISA with specific anti-mouse mAbs for capture and detection utilizing BD OptEIA (IFN- $\gamma$; BD Biosciences) or ELISA MAX (IL-17A; Biolegend). Assays were performed according to the manufacturers' protocols and read at $450 \mathrm{~nm}$ using a microplate reader (Model 3550; Bio-Rad Labs). All samples and standards were run in duplicate.

Cell proliferation dye and apoptosis analysis. T cells isolated from either B6 WT or Siglec-G $\mathrm{G}^{-/-}$animals were washed and resuspended at a concentration of $1 \times 10^{6}$ cells $/ \mathrm{ml}$ in PBS containing $0.1 \%$ BSA. Cell proliferation dye eFluor 670 (eBioscience) in dimethylsulfoxide (DMSO) (5 mM) was added to the T cell suspension to a final concentration of $2 \mu \mathrm{M}$. The cells were gently mixed and incubated at $37^{\circ} \mathrm{C}$ for 10 minutes. The staining was quenched by the addition of Roswell Park Memorial Institute (RPMI) medium containing $10 \%$ fetal calf serum (FCS), and the cells were washed 3 times and then used in in vitro assays. After 24 hours, the cells were stained with a PE-conjugated anti-annexin-V mAb (Biolegend) and Per CPCy5.5-conjugated anti-90.2 mAb (Biolegend) in the dark for 15 minutes at room temperature in labeling buffer and analyzed using an Accuri C6 cytometer (BD Bioscience). 
Western blot analysis. T cells were incubated with anti-CD3 $(2 \mu \mathrm{g} / \mathrm{ml})$ and CD28 $(1 \mu \mathrm{g} / \mathrm{ml})$ antibody with or without HMBG-1 $(10 \mu \mathrm{g} / \mathrm{ml})$ in 24 -well plates for 3, 6, 12, and 24 hours. Following incubation, $\mathrm{T}$ cells were harvested and washed with PBS and then whole-cell lysates were obtained and protein concentrations determined with a Pierce BCA Protein Assay (Thermo Fisher Scientific). Equal amounts of protein were separated by 10\% SDS-PAGE gel (120 V, 1.5 hours) and subsequently transferred to nitrocellulose membranes $(20 \mathrm{~V}, 1$ hour). The following antibodies were used to analyze the membranes: anti-rabbit STAT-3 (79D7), anti-rabbit p-STAT-3 (Y705), anti-rabbit LCK, and antirabbit p-LCK (Y505) purchased from Cell Signaling Technology. Secondary antibodies conjugated to HRP (Jackson ImmunoResearch) were used to detect primary antibodies. Densitometric analysis was performed using ImageJ software (NIH). For testing SHP-1 and p-SHP-1 expression, T cells were harvested at day 7 after BMT and whole-cell lysates were prepared as described above. Briefly, cell pellets were washed twice with cold PBS, resuspended in cell lysis buffer $(20 \mathrm{mM}$ Hepes, pH 7.9 with $400 \mathrm{mM}$ $\mathrm{NaCl}, 1 \mathrm{mM}$ EDTA, $1 \mathrm{mM}$ DTT, $0.5 \mathrm{mM}$ phenylmethylsulfonyl fluoride, $1 \mu \mathrm{g} / \mathrm{ml}$ pepstatin A, $10 \mu \mathrm{g} /$ $\mathrm{ml}$ leupeptin, and $10 \mu \mathrm{g} / \mathrm{ml}$ aprotinin). Protein concentration was quantified, and equivalent amounts of protein sample (10-20 $\mu \mathrm{g})$ were electrophoresed in NuPAGE Novex 4\%-12\% Bis-Tris gels, and transferred to PVDF membranes, followed by incubation with primary antibodies (polyclonal rabbit anti-ppSHP-1, total SHP-1, $\beta$-actin, Cell Signaling; 1:1,000) and appropriate secondary antibodies. The bands were visualized by using a Pierce enhanced chemiluminescence system, and analyzed by densitometry. p-SHP-1 levels were normalized to that of total SHP-1/2 bands, respectively. Each result represents the average value of 2 independent experiments \pm standard deviation.

Treatment with CD24 fusion protein. In the in vivo experiments, the BALB/c WT and CD $24^{-/-} \mathrm{BALB} / \mathrm{c}$ animals received $850 \mathrm{cGy}$ total body irradiation $\left({ }^{137} \mathrm{Cs}\right.$ source) on day -1 and then received an intravenous injection of $5 \times 10^{6} \mathrm{BM}$ cells plus isolated $0.75 \times 10^{6} \mathrm{CD} 90^{+} \mathrm{T}$ cells from a donor on day 0 . CD24Fc, comprising the extracellular domain of CD24 and IgG Fc (provided by OncoImmune) $(5 \mathrm{mg} / \mathrm{kg})$ and an equivalent dose of PBS were administered i.p. on day 0 of all-HCT (40).

Induction of leukemia and lymphoma. Tumors (P815, H-2 $)$ were purchased from American Type Culture Collection (ATCC) and introduced during BMT at 2 different doses as described previously (41). To observe GVT responses, we utilized the lower dose of tumor cells (P815, $1 \times 10^{3}$ to $5 \times 10^{3} /$ mouse) because even at this low dose we already established that the animals cannot reject the tumor cells and that this tumor is uniformly lethal and results in tumor infiltration and engraftment of the liver and spleen with characteristic nodule formation or hind-limb paralysis caused by spinal cord infiltration (41). We concluded that tumor contributed to death only if the tumor was present at the necropsy. Death was attributed to GVHD alone only if no tumor was evident and there was histologic evidence of GVHD. Mice surviving beyond the observation period of BMT were sacrificed for histological evaluation to determine leukemia- and lymphoma-free survival.

Bioluminescence imaging. Bioluminescence imaging was performed with a cryogenically cooled CCD camera (IVIS, Caliper Life Sciences). Acquisition and analysis of images were performed as previously described (41). All animals were imaged 10 minutes after being injected i.p. with $100 \mu 1(40 \mathrm{mg} / \mathrm{ml})$ of firefly D-luciferin (Biosynth International Inc.). Animals were imaged 30 seconds to 5 minutes, depending on the signal strength. All animals were maintained under isoflurane anesthesia and in a $37^{\circ} \mathrm{C}$ environment.

${ }^{51} \mathrm{Cr}$-release assay. Donor splenocytes from the recipient animals were harvested and normalized for donor $\mathrm{CD}^{+} \mathrm{T}$ cells and then utilized directly as effector cells. MBL-2 (H-2 ${ }^{\mathrm{b}}$ for syngeneic) and P815 (H-2 ${ }^{\mathrm{d}}$ for allogeneic) were labeled $\left(2 \times 10^{6}\right.$ cells) with $2 \mathrm{MBq} \mathrm{Na}_{2}{ }^{51} \mathrm{CrO}_{4}$ (PerkinElmer Life) for 1.5 hours at $37^{\circ} \mathrm{C}$ in a $5 \% \mathrm{CO}_{2}$ atmosphere and used as target cells. After washing, $5 \times 10^{3}$ labeled targets were resuspended and the ${ }^{51} \mathrm{Cr}$-release assay was performed. These preparations were added to triplicate wells at varying effector-to-target ratios and incubated for 4 hours. Maximal and background release was determined by the addition of Triton X-100 (Sigma-Aldrich) or media alone to targets, respectively. ${ }^{51} \mathrm{Cr}$ activity in supernatants taken 4 hours later was determined in an autogamma counter (Packard).

Human PBMC isolation. Studies with human cells were performed after obtaining informed consent from the participants; informed consent was obtained in accordance with the Declaration of Helsinki. The University of Michigan Institutional Review Board approved the studies (approval number, HUM0043287). Peripheral blood samples were collected from participants and then isolated with utilizing Ficoll-Paque PREMIUM solution (GE Healthcare Bio Science). In some experiments, Siglec-10 depleted PBMCs were obtained by purification with APC-conjugated mAbs against human Siglec-10 (clone 5G6, Miltenyi Biotec) and anti-APC microbeads by MACS. PBMCs $\left(1 \times 10^{6} / \mathrm{ml}\right)$ were plated 
on dishes precoated with anti-CD3 $\mathrm{mAb}(10 \mu \mathrm{g} / \mathrm{ml}$, clone OKT3, Biolegend $)$ and cultured with antiCD28 mAb (2 $\mu \mathrm{g} / \mathrm{ml}$, clone CD28.2, Biolegend) and human HMGB-1 protein $(5 \mu \mathrm{g} / \mathrm{ml}$, ProSpec-Tany Technologies Ltd.) for 48 hours. CD24Fc $(10 \mu \mathrm{g} / \mathrm{ml})$ or diluent control was added during the reaction. PBMCs were prestimulated with HMGB-1 for 4 hours and washed twice with PBS and then plated in some experiments. For Siglec-10 expression in $\mathrm{CD}^{+} \mathrm{T}$ cells, PBMCs were stained with FITC-conjugated mAbs against human CD3 (clone HIT3a, Biolegend) according to the manufacturer's protocol.

Statistics. The Mann-Whitney $U$ test was used for the statistical analysis of in vitro data, and the Wilcoxon rank test was used to analyze survival data. For analyzing the changes within the sample a paired $t$ test was utilized. A $P$ value less than 0.05 was considered statistically significant. In experiments that included more than 2 groups, a Bonferroni correction was used to adjust $P$ values for multiple comparisons.

Study approval. All animals were cared for according to regulations reviewed and approved by the University Committee on Use and Care of Animals of the University of Michigan, based on University Laboratory Animal Medicine guidelines (PRO00007573).

Studies with human cells were performed after obtaining informed consent from the participants; informed consent was obtained in accordance with the Declaration of Helsinki. The University of Michigan Institutional Review Board approved the studies (approval number, HUM0043287).

\section{Author contributions}

TT designed and performed experiments, analyzed the data, and wrote the paper. CR performed experiments and analyzed the data. KOW, CZ, SB, HT, HF, JW, and YS performed experiments. CL performed experiments and histopathological analysis. TB helped with statistical analysis. JM helped to write the manuscript. PZ contributed reagents and helped to write the manuscript. YL analyzed the data, contributed reagents, and helped to write the manuscript. PR designed experiments, analyzed the data, and wrote the manuscript.

\section{Acknowledgments}

This work was supported by NIH grants HL090775, CA173878, HL128046, and CA203542, and an American Society of Blood and Marrow Transplantation New Investigator Award (to T.T.).

Address correspondence to: Pavan Reddy, Department of Internal Medicine, Division of Hematology and Oncology, Blood and Marrow Transplantation Program, University of Michigan Comprehensive Cancer Center, 3312 CCGC, 1500 E. Medical Center Drive, Ann Arbor, Michigan, 48105-1942, USA. Phone: 734.936.5280; Email: reddypr@med.umich.edu.

1. Iwasaki A, Medzhitov R. Regulation of adaptive immunity by the innate immune system. Science. 2010;327(5963):291-295

2. Mills KH. TLR-dependent T cell activation in autoimmunity. Nat Rev Immunol. 2011;11(12):807-822.

3. Crocker PR, Paulson JC, Varki A. Siglecs and their roles in the immune system. Nat Rev Immunol. 2007;7(4):255-266

4. Macauley MS, Crocker PR, Paulson JC. Siglec-mediated regulation of immune cell function in disease. Nat Rev Immunol. 2014;14(10):653-666.

5. Ding C, et al. Siglecg limits the size of B1a B cell lineage by down-regulating NFkappaB activation. PLoS One. $2007 ; 2$ (10):e997.

6. Hoffmann A, et al. Siglec-G is a B1 cell-inhibitory receptor that controls expansion and calcium signaling of the B1 cell population. Nat Immunol. 2007;8(7):695-704.

7. Chen GY, Tang J, Zheng P, Liu Y. CD24 and Siglec-10 selectively repress tissue damage-induced immune responses. Science. 2009;323(5922):1722-1725.

8. Chen GY, et al. Amelioration of sepsis by inhibiting sialidase-mediated disruption of the CD24-SiglecG interaction. Nat Biotech nol. 2011;29(5):428-435

9. Chen W, et al. Induction of Siglec-G by RNA viruses inhibits the innate immune response by promoting RIG-I degradation. Cell. 2013;152(3):467-478.

10. Duong BH, et al. Decoration of T-independent antigen with ligands for CD22 and Siglec-G can suppress immunity and induce B cell tolerance in vivo. J Exp Med. 2010;207(1):173-187.

11. Ferrara JL, Levine JE, Reddy P, Holler E. Graft-versus-host disease. Lancet. 2009;373(9674):1550-1561.

12. Liu Y, Chen GY, Zheng P. CD24-Siglec G/10 discriminates danger-from pathogen-associated molecular patterns. Trends Immunol. 2009;30(12):557-561.

13. Wilhelm K, et al. Graft-versus-host disease is enhanced by extracellular ATP activating P2X7R. Nat Med. 2010;16(12):1434-1438

14. Hill GR, Crawford JM, Cooke KR, Brinson YS, Pan L, Ferrara JL. Total body irradiation and acute graft-versus-host disease: the role of gastrointestinal damage and inflammatory cytokines. Blood. 1997;90(8):3204-3213.

15. Akira S, Uematsu S, Takeuchi O. Pathogen recognition and innate immunity. Cell. 2006;124(4):783-801.

16. Shlomchik WD, et al. Prevention of graft versus host disease by inactivation of host antigen-presenting cells. Science. 
1999;285(5426):412-415.

17. Teshima T, et al. Acute graft-versus-host disease does not require alloantigen expression on host epithelium. Nat Med. 2002;8(6):575-581.

18. Toubai T, et al. Siglec-G-CD24 axis controls the severity of graft-versus-host disease in mice. Blood. 2014;123(22):3512-3523.

19. Hutzler S, et al. The ligand-binding domain of Siglec-G is crucial for its selective inhibitory function on B1 cells. J Immunol. 2014;192(11):5406-5414.

20. Pfrengle F, Macauley MS, Kawasaki N, Paulson JC. Copresentation of antigen and ligands of Siglec-G induces B cell tolerance independent of CD22. J Immunol. 2013;191(4):1724-1731.

21. Liu W, Zhang L, Wei Z, Chen S, Chen G. Analysis of beta-agonists and beta-blockers in urine using hollow fibre-protected liquid-phase microextraction with in situ derivatization followed by gas chromatography/mass spectrometry. J Chromatogr A. 2009;1216(28):5340-5346.

22. He Y, Zha J, Wang Y, Liu W, Yang X, Yu P. Tissue damage-associated “danger signals" influence T-cell responses that promote the progression of preneoplasia to cancer. Cancer Res. 2013;73(2):629-639.

23. Bandala-Sanchez E, et al. T cell regulation mediated by interaction of soluble CD52 with the inhibitory receptor Siglec-10. Nat Immunol. 2013;14(7):741-748

24. Pillai S, Netravali IA, Cariappa A, Mattoo H. Siglecs and immune regulation. Annu Rev Immunol. 2012;30:357-392.

25. Macauley MS, Paulson JC. Siglecs induce tolerance to cell surface antigens by BIM-dependent deletion of the antigen-reactive B cells. J Immunol. 2014;193(9):4312-4321.

26. Fang X, Zheng P, Tang J, Liu Y. CD24: from A to Z. Cell Mol Immunol. 2010;7(2):100-103.

27. Li H, et al. Profound depletion of host conventional dendritic cells, plasmacytoid dendritic cells, and B cells does not prevent graft-versus-host disease induction. J Immunol. 2012;188(8):3804-3811.

28. Matte-Martone C, et al. Recipient B cells are not required for graft-versus-host disease induction. Biol Blood Marrow Transplant. 2010;16(9):1222-1230.

29. Kristiansen G, Sammar M, Altevogt P. Tumour biological aspects of CD24, a mucin-like adhesion molecule. J Mol Histol. 2004;35(3):255-262.

30. Baumann P, et al. CD24 expression causes the acquisition of multiple cellular properties associated with tumor growth and metastasis. Cancer Res. 2005;65(23):10783-10793.

31. Overdevest JB, Thomas S, Kristiansen G, Hansel DE, Smith SC, Theodorescu D. CD24 offers a therapeutic target for control of bladder cancer metastasis based on a requirement for lung colonization. Cancer Res. 2011;71(11):3802-3811.

32. Wang L, et al. Intracellular CD24 disrupts the ARF-NPM interaction and enables mutational and viral oncogene-mediated p53 inactivation. Nat Commun. 2015;6:5909.

33. Nielsen PJ, et al. Altered erythrocytes and a leaky block in B-cell development in CD24/HSA-deficient mice. Blood. 1997;89(3):1058-1067.

34. Reddy P, Maeda Y, Liu C, Krijanovski OI, Korngold R, Ferrara JL. A crucial role for antigen-presenting cells and alloantigen expression in graft-versus-leukemia responses. Nat Med. 2005;11(11):1244-1249.

35. Reddy $\mathrm{P}$, et al. Histone deacetylase inhibition modulates indoleamine 2,3-dioxygenase-dependent DC functions and regulates experimental graft-versus-host disease in mice. J Clin Invest. 2008;118(7):2562-2573.

36. Cooke KR, et al. Tumor necrosis factor- alpha production to lipopolysaccharide stimulation by donor cells predicts the severity of experimental acute graft-versus-host disease. J Clin Invest. 1998;102(10):1882-1891.

37. Hill GR, et al. Interleukin-11 promotes $\mathrm{T}$ cell polarization and prevents acute graft-versus-host disease after allogeneic bone marrow transplantation. J Clin Invest. 1998;102(1):115-123.

38. Toubai T, et al. Ikaros-Notch axis in host hematopoietic cells regulates experimental graft-versus-host disease. Blood. 2011;118(1):192-204.

39. Toubai T, et al. Induction of acute GVHD by sex-mismatched H-Y antigens in the absence of functional radiosensitive host hematopoietic-derived antigen-presenting cells. Blood. 2012;119(16):3844-3853.

40. Zheng X, Wu W, Liu Y, Zheng P, inventors; Oncoimmune, Inc., applicant. Methods of use of soluble CD24 for therapy of rheumatoid arthritis. WIPO patent application WO2011139820 A8. April 28, 2011.

41. Duran-Struuck R, et al. A novel role for the semaphorin Sema4D in the induction of allo-responses. Biol Blood Marrow Transplant. 2007;13(11):1294-1303. 